\title{
1 Rootstocks influence the response of ripening grape berries to 2 leafroll associated viruses
}

4 Amanda M. Vondras ${ }^{1}$, Larry Lerno ${ }^{1}$, Mélanie Massonnet ${ }^{1}$, Andrea Minio ${ }^{1}$, Adib Rowhani ${ }^{2}$,

5 Dingren Liang ${ }^{1}$, Jadran Garcia ${ }^{1}$, Daniela Quiroz $^{1}$, Rosa Figueroa-Balderas ${ }^{1}$, Deborah A. Golino ${ }^{2}$,

6 Susan E. Ebeler ${ }^{1}$, Maher Al Rwahnih ${ }^{2}$, Dario Cantu ${ }^{1 *}$

7

8 1. Department of Viticulture and Enology, University of California, Davis, CA 95616

9 2. Department of Plant Pathology, University of California, Davis, CA 95616

$10 *$ Corresponding author: dacantu@ucdavis.edu 


\section{Abstract}

2 Grapevine leafroll-associated virus (GLRaV) infections are accompanied by symptoms

3 with varying severity. Using a dedicated experimental vineyard, we studied the responses to

4 GLRaVs in ripening berries from Cabernet franc grapevines grafted to different rootstocks and

5 with zero, one, or pairs of leafroll infection(s). RNA sequencing data were mapped to a high-

6 quality Cabernet franc genome reference assembled to carry out this study and integrated with

7 hormone and metabolite abundance data. This study identified several molecular levers that

8 participate in responses to GLRaVs, including those that are condition-dependent. This included

9 describing common responses to GLRaVs that were reproduced in two consecutive years, in

10 plants grafted to different rootstocks, and in more than one infection condition. Though different

11 infections were inconsistently distinguishable from one another overall, the effects of infections

12 in plants grafted to different rootstocks were distinct at each developmental stage. Conserved

13 responses included the modulation of pathogen detecting genes, increases in abscisic acid

14 signaling and cytoskeleton remodeling gene expression. The abundance of abscisic acid (ABA),

15 related metabolites, $\mathrm{ABA}$ and hormone signaling-related gene expression, and the expression of

16 several transcription factor families differentiated rootstocks overall. These data show that

17 rootstock influences the effect of GLRaVs in ripening berries.

\section{Keywords}

20 Berry ripening, Closteroviridae, GLRaV, leafroll disease, mixed virus infections, ,

21 phytohormone, plant-virus interaction, rootstock, secondary metabolism, Vitis vinifera 


\section{Introduction}

Grapevine leafroll-associated viruses (GLRaVs) are among the most consequential

pathogens affecting grapevine and have considerable economic impact (Atallah et al., 2012;

Ricketts et al., 2015). GLRaVs are diverse and belong to the family Closteroviridae, with five

5 different species and numerous strains in three genera (Naidu et al., 2015). Grapevines are often infected with several of these viruses simultaneously (Prosser et al., 2007; Rwahnih et al., 2009; Fuchs et al., 2021). Given their impact and global distribution, efforts to manage the spread of

8 GLRaV, characterize their effects, and understand the interaction between the vine and pathogens have been undertaken.

Generally, plant responses to viruses include numerous changes in gene expression, gene regulation, and metabolism (Alazem \& Lin, 2015; Moon \& Park, 2016; Bester et al., 2016;

12 Blanco-Ulate et al., 2017). Diverse pathogens and stresses elicit conserved responses from their

13 hosts (Postnikova \& Nemchinov, 2012; Shaik \& Ramakrishna, 2013; Amrine et al., 2015; Jiang

14 et al., 2015) and phylogenetically related viruses elicit similar responses (Rodrigo et al., 2012).

15 Infections with GLRaVs have been associated with poorer fruit quality, lower yield, and leaves

16 that curl, redden, and become brittle. Gene expression studies that implicate regulatory systems

17 in the leafroll disease phenotype are few in number and have focused on the impact of GLRaV-3,

18 highlighting changes in the expression of senescence-associated and flavonoid biosynthetic pathway genes (Espinoza et al., 2007b,a; Gutha et al., 2010; Vega et al., 2011). Additional transcriptomic study could help generate novel hypotheses concerning the controls that are

21 fundamental to GLRaV responses (Mandadi \& Scholthof, 2013; Gaiteri et al., 2013; Moon \&

22 Park, 2016); phytohormone signaling pathways and other molecular controls with far-reaching

23 influence on the transcriptome are good candidates.

Though common responses might be expected in infected plants given the relatedness of

25 GLRaVs, there is considerable variability in the severity of GLRaV infections. Some GLRaV

26 infections appear asymptomatic or are mild (Kovacs et al., 2001; Poojari et al., 2013; Montero et

27 al., 2016), but others cause significant changes in photosynthesis, metabolism, and gas exchange

28 in leaves (Guidoni et al., 1997; 2000; Bertamini et al., 2004; Pereira et al., 2012; Endeshaw et

29 al., 2014). Changes in fruit yield, organic and amino acids, titratable acidity, potassium, sugars, 30 and flavonoids are also observed (Kliewer \& Lider, 1976a; Cabaleiro et al., 1999; Lee \& Martin, 31 2009; Lee et al., 2009; Alabi et al., 2016). These are influenced by host genotype (Kovacs et al., 
1 2001; Montero et al., 2016), which virus or combination of viruses is present (Credi, 1997;

2 Guidoni et al., 2000; Komar et al.), and environmental conditions (Cui et al., 2016).

Evidence relating GLRaV responses to rootstock is mixed (Golino, 1993; Komar et al.,

4 2010). In a study of Cabernet franc vines grafted to different rootstocks, the effect of GLRaV

5 infection on pruning weight depended on rootstock and the largest effects across all the

6 parameters considered were observed in Kober 5BB-grafted vines (Rowhani, 2015). Similarly,

7 fruit yield was influenced by both infection type and rootstock, with Kober 5BB-grafted vines

8 most severely affected by a mixed infection with GLRaV-2, GLRaV-3, and Grapevine fleck

9 virus (Golino et al., 2008b). In an extreme example, Red Globe scion buds infected with a strain

10 of GLRaV-2 (formerly named Grapevine rootstock stem lesion associated virus) were used to

11 inoculate Cabernet Sauvignon plants grafted to 18 different rootstocks; the infection was lethal in

12 several rootstock conditions, including Kober 5BB (Uyemoto et al., 2001; Alkowni et al., 2011).

13 This study used Cabernet franc grapevines infected with zero, one, or two GLRaVs and

14 grafted to two different rootstocks to identify responses to leafroll viruses in ripening berries that

15 were conserved across experimental conditions and to determine whether or not GLRaV

16 responses could be distinguished in the berries of plants grafted to different rootstocks.

17 Grapevines were grown in a single experimental vineyard and berries were sampled during

18 ripening in four consecutive years. Measures of vine growth and fruit composition were taken in

19 the first two years. Total soluble solids (TSS) were measured in all four years. In the third and

20 fourth years, RNA sequencing (RNAseq) and metabolite data were collected from Cabernet

21 franc berries at four stages during ripening. RNAseq reads were mapped to the Cabernet franc

22 genome, which was sequenced in long PacBio reads, assembled using the FALCON-Unzip

23 pipeline, and scaffolded using Hi-C data. The same samples were used to measure stress and

24 ripening-associated phytohormones, including abscisic acid (ABA), jasmonic acid (JA), and

25 salicylic acid (SA), and ripening-related metabolites. Though many of the GLRaV effects

26 occurred in individual years, a subset of reproducible conserved responses and rootstock-driven

27 differences were discovered. 


\section{Materials and methods}

2 Vineyard establishment

The experimental vineyard used in this study consists of Cabernet franc clone 04 (UC

4 Davis, Foundation Plant Services, https://fps.ucdavis.edu/fgrdetails.cfm?varietyid=355; accessed

5 March 2, 2021) grapevines grafted on different rootstocks and infected with zero, individual, or pairs of GLRaVs. All rootstocks and Cabernet franc scions were tested for grapevine pathogens. Total nucleic acid (TNA) extracts were prepared from all rootstocks and Cabernet franc scions as described by Al Rwahnih et al. (2017) (Rwahnih et al., 2017). Briefly, approximately 0.2 grams of leaf petioles were homogenized using a HOMEX 6 homogenizer (Bioreba AG, Reinach,

11 (ThermoFisher Scientific) per the manufacturer's protocol. Extracted TNA samples were

12 analyzed by reverse transcription quantitative PCR (RT-qPCR) using TaqMan probes on the

13 QuantStudio 6 Flex Real-Time PCR System (ThermoFisher Scientific) as described previously

14 (Osman et al., 2008; Klaassen et al., 2011; Rwahnih et al., 2017). The samples were screened for 15 the following pathogens: Grapevine leafroll-associated virus-1, Grapevine leafroll-associated

16 virus-3, Grapevine leafroll-associated virus-4 (plus strains 5, 6, 9, Pr and Car;

17 genus Ampelovirus), Grapevine leafroll-associated virus-2 (plus strain 2RG; genus Closterovirus), Grapevine leafroll-associated virus-7 (genus Velarivirus), Grapevine fleck virus (genus Maculavirus), Grapevine rupestris vein feathering virus (genus Marafivirus), Grapevine fanleaf virus, Tobacco ringspot virus, Tomato ringspot

21 virus (genus Nepovirus), Grapevine virus A, Grapevine virus B, Grapevine virus D, Grapevine

22 virus E, Grapevine virus F, (genus Vitivirus), Grapevine red blotch virus

23 (genus Grablovirus), Grapevine rupestris stem-pitting associated virus (genus Foveavirus),

24 phytoplasmas and Xylella fastidiosa, the causative agent of Pierce's disease.

In Fall 2008, Cabernet franc grapevines were bench-grafted onto rootstocks, including Millardet et de Grasset (MGT) 101-14 and Kober 5BB. These plants were subsequently grown in

27 a greenhouse. Between 2009 and 2011, the rootstock portions of these plants were inoculated with two chip buds from single leafroll-infected plants. Infected plants used for chip buds were reconfirmed by RT-qPCR. Plants infected with a single species of GLRaV received two identical chip buds. Plants infected with two species of GLRaVs also received two chip buds, each carrying a single virus. Plants infected with GLRaV-1, GLRaV-2 and/or GLRaV-3 were 
1 inoculated with two or more isolates of each species of GLRaV. The inoculated plants were kept

2 in a greenhouse for approximately one month, acclimatized, then were planted in the field.

3 Healthy controls included non-chip budded plants and plants chip budded from a healthy source.

4 The vines were planted according to a randomized complete block design, with seven feet

5 between vines and nine feet between rows. One group of five vines was planted per rootstock $\times$

6 infection condition in each of three blocks. Healthy vines were distributed throughout each block

7 to monitor the spread of viruses, and experimental vines were sampled yearly to test and reaffirm

8 the vines' infection status. A buffer zone of healthy vines was planted as a barrier between the

9 leafroll vineyard and other vineyards in the area. Vines were trained with a bilateral cordon and

10 spur pruned.

Cabernet franc genome sequencing and assembly

13 High quality genomic DNA were isolated from grape leaves using the method described

14 in Chin et al. (2016). DNA purity was evaluated with a Nanodrop 2000 spectrophotometer

15 (Thermo Scientific, Hanover Park, IL), quantity with a Qubit 2.0 Fluorometer (Life

16 Technologies, Carlsbad, CA), and integrity by electrophoresis. SMRTbell libraries were prepared

17 for Cabernet franc clone 04 as described by Massonnet et al. (2020). Final libraries were evaluated for quantity and quality using a Bioanalyzer 2100 (Agilent Technologies, CA) and sequenced on a PacBio RS II (DNA Technology Core Facility, University of California, Davis).

De novo assembly of Cabernet franc clone 04 (UC Davis, Foundation Plant Services,

21 https://fps.ucdavis.edu/fgrdetails.cfm?varietyid=355; accessed March 2, 2021) was performed

22 using PacBio RS II data and FALCON-Unzip (v. 1.7.7; (Chin et al., 2016). Repetitive sequences

23 were masked before and after read error-correction using TANmask and REPmask modules in

24 Damasker (Myers, 2014). Multiple FALCON-Unzip parameters were tested to optimize the

25 assembly as described in Minio et al., 2019(Minio et al., 2019a). Haplotype reconstruction was

26 performed with default parameters. Finally, contigs were polished with Quiver (Pacific

27 Biosciences, bundled with FALCON-Unzip v. 1.7.7).

28 The primary assembly was scaffolded to reduce sequence fragmentation. First, primary

29 contigs were scaffolded with SSPACE-LongRead (v.1.1; (Boetzer \& Pirovano, 2014). Junctions

30 supported by at least 20 reads (“-1 20”) were allowed. Hi-C data and the proprietary HiRise

31 software (v1.3.0-1233267alcde) were used for hybrid scaffolding. A Dovetail Hi-C library was 
1 prepared by Dovetail Genomics (Scotts Valley, CA, USA) as described in Lieberman-Aiden et

2 al. (2009) (Lieberman-Aiden et al., 2009) and sequenced on an Illumina platform, generating $2 \times$

3 150bp paired-end reads.

4 The repeat and gene annotation were performed as reported in Vondras et al. (2019)

5 (Vondras et al., 2019). Briefly, RepeatMasker (v. open-4.0.6; (Smit et al.)) and a custom $V$.

6 vinifera repeat library (Minio et al., 2019b) were applied to identify repetitive elements in the

7 genome. To annotate genes, publicly available datasets were used as evidence for gene

8 prediction. Transcriptional evidence included Vitis ESTs, Cabernet Sauvignon corrected Iso-Seq

9 reads (Minio et al., 2019b), Tannat (Da Silva et al., 2013), Corvina (Venturini et al., 2013), and

10 Cabernet Sauvignon transcriptomes (Massonnet et al., 2020), and previously published RNAseq

11 data (PRJNA260535). Swissprot viridiplantae data and Vitis data were used as experimental

12 evidence. Each RNAseq sample was trimmed with Trimmomatic (v. 0.36; (Bolger et al., 2014))

13 and assembled with Stringtie (v. 1.3.3; (Pertea et al., 2015)). This data was mapped on the

14 genome using Exonerate (v. 2.2.0, transcripts and proteins; (Slater \& Birney, 2005)) and PASA

15 (v. 2.1.0, transcripts; (Haas et al., 2003)). Alignments and ab initio predictions generated with

16 SNAP (ver. 2006-07-28; (Korf, 2004)), Augustus (ver. 3.0.3; (Stanke et al., 2006)), and

17 GeneMark-ES (ver. 4.32; (Lomsadze et al., 2005)) were used as input for EVidenceModeler (v.

18 1.1.1; (Haas et al., 2008)). EVidenceModeler was used to identify consensus gene structures. A

19 functional annotation was obtained using the RefSeq plant protein database

20 (ftp://ftp.ncbi.nlm.nih.gov/refseq, retrieved January 17th, 2017; (Jones et al., 2014)) as in Minio

21 et al. (2019).

22

\section{Sampling and sample preparation}

Berries from Cabernet franc grapevines grafted to Kober 5BB or MGT 101-14 and

25 infected with either GLRaV-1 (GLRaV-1 (+)), GLRaV-3 (GLRaV-3 (+)), GLRaV-4 (strain 5;

26 GLRaV-4 (+)), GLRaV-1 and GLRaV-2 (GLRaV-1,2 (+)), or GLRaV-1 and GLRaV-3

27 (GLRaV-1,3 (+)) were sampled during ripening in 2017 and 2018. In both years, fruits were sampled at pre-véraison, véraison, mid-ripening, and at commercial harvest. These stages correspond to modified Eichhorn-Lorenz (Coombe, 1995) stages 34 (green berries beginning to

30 soften and ${ }^{\circ}$ Brix starts increasing), 35 (berries begin to change color and enlarge, $\sim 50 \%$ of

31 berries within clusters show color transition), 36/37 (berries with intermediate ${ }^{\circ}$ Brix values / 
1 berries are not quite ripe), and 38 (berries are harvest-ripe). Effort was made to sample fruits in

22018 at developmental stages comparable to 2017, as determined by TSS. In 2017, berries were 3 sampled July $7^{\text {th }}$, July $31^{\text {st }}$, August $14^{\text {th }}$, and August $31^{\text {st }}$. In 2018 , berries were sampled June $28^{\text {th }}$, 4 July $30^{\text {th }}$, August $13^{\text {th }}$, and August $30^{\text {th }}$.

$5 \quad$ On each sampling date, six biological replicates were taken, with berries from one plant constituting one biological replicate. Two biological replicates per condition were sampled from each of three blocks. There were two exceptions. For Kober 5BB-grafted GLRaV-1,2 (+), three

8 biological replicates were drawn from each of two plants in one block. For Kober 5BB-grafted GLRaV-3 (+), two of the six biological replicates were drawn from one plant. Approximately twenty berries were sampled per plant, with equal numbers of berries sampled from each side of the vine. Samples were then temporarily cooled on ice.

Samples were processed immediately following sampling. This included rinsing berries with deionized water, deseeding them, and snap-freezing them in liquid nitrogen. Berries were

14 stored at $-80{ }^{\circ} \mathrm{C}$ until crushed into a fine powder while frozen using a mechanical mill. Total

15 soluble solids were subsequently measured in technical triplicate using a digital refractometer.

16 Four of six biological replicates, a total of 192 samples per year, were used for subsequent RNA

17 sequencing and LC-MS.

RNA extraction and sequencing library preparation

Total RNA was extracted from two grams of finely ground berry pericarp tissue as

21 previously described (Blanco-Ulate et al., 2013). RNA purity was evaluated with a Nanodrop

222000 spectrophotometer (Thermo Scientific, Hanover Park, IL), quantity with a Qubit 2.0

23 Fluorometer (Life Technologies, Carlsbad, CA), and integrity by electrophoresis. RNAseq

24 libraries were prepared using the Illumina TruSeq RNA sample preparation kit v.2 (Illumina,

25 CA, USA) and barcoded individually following the manufacturer's protocol. Final libraries were 26 evaluated for quantity and quality with the High Sensitivity chip in a Bioanalyzer 2100 (Agilent 27 Technologies, CA).

Libraries were sequenced as 100 base-pair, single-end reads, using an Illumina HiSeq4000 sequencer (DNA Technology Core Facility, University of California, Davis)

30 producing an average of $18.07 \mathrm{M} \pm 4.56 \mathrm{M}$ reads per sample in 2017 and $14.69 \mathrm{M} \pm 2.11 \mathrm{M}$ reads 31 per sample in 2018. 
RNAseq data analysis

RNAseq reads were trimmed using Trimmomatic (v. 0.36; (Bolger et al., 2014)) and the

4 following settings: Leading:2, Trailing:2, Sliding window:4:20, Min length:70. Reads were

5 mapped to the primary assembly of the Cabernet franc genome using HISAT2 (-k 1; v. 2.0.5;

6 (Kim et al., 2015)) and counts were generated using htseq-count with default parameters (v.

$7 \quad 0.9 .0 ;$ (Anders et al., 2015)).

8 All subsequent analyses were done using R (R Core Team, 2020) in the R Studio environment (R Studio Team, 2020). Data normalization and differential expression analyses were done using DESeq2 (v. 1.24.0; (Love et al., 2014)). A variance stabilizing transformation

11 (VST) was applied to expression data using DESeq2. VST data were centered in each GLRaV

$12(+)$ condition relative to the mean expression per gene in GLRaV (-) given the same time,

13 rootstock, and year.

14 Centered data were used for Multiple Factor Analysis (MFA). The FactoMineR R 15 package was used for MFA (Le et al., 2008). Genes were included in the MFA if they were 16 differentially expressed (1) versus GLRaV (-) and/or if the effects of an infection differed

17 between rootstocks (2) in at least one year $(\mathrm{P}<0.05)$, and (3) if the direction of the effect relative to GLRaV (-) was consistent in both years, even if a significant effect was only observed in one year. An MFA was repeated for each developmental stage separately. All hormone and metabolite data were included.

Statistical overrepresentation tests were done using the clusterProfiler R package (Yu et

22 al., 2012) and VitisNet functional categories (Grimplet et al., 2009). To make use of the VitisNet

23 functional annotations, Cabernet franc genes were used to query Pinot noir PN40024 sequences

24 with blastp (Altschul et al., 1990). The best hits, with no less than $80 \%$ reciprocal identity and 25 coverage, were retained.

A curated list of ABA biosynthetic pathway and signaling genes annotated in PN40024

27 was retrieved from Pilati et al., 2017 (Pilati et al., 2017)(Supplementary File S1). As described above, Cabernet franc genes were used to query Pinot noir PN40024 sequences with blastp (Altschul et al., 1990). The best hits were retained; all target-query pairs had no less than 30 reciprocal 97\% identity and 86\% reciprocal coverage (median coverage, 99\%). 
Hormone extraction and LC-MS/MS

Approximately fifty milligrams (mean $50.86 \pm 3.33 \mathrm{mg}$ ) of berry powder were weighed for the extraction and quantitation of ABA, SA, and JA. Exact weights were recorded to later calculate the exact amount of each of these analytes per milligram of fresh tissue. The same

5 samples used for RNA sequencing were used for this analysis. Four biological replicates were used. Extractions and analyses were randomized and performed in technical duplicate.

Hormones were extracted following a method described by Pan et al., (2010) with a few

8 modifications (Pan et al., 2010). Samples were subjected to $500 \mathrm{~mL}$ of 2-propanol: $\mathrm{H}_{2} \mathrm{O}: \mathrm{HCl}$

9 (2:1:0.002) and spiked with $50 \mathrm{ng}$ of $\mathrm{d}_{6}$ abscisic acid, $\mathrm{d}_{5}$ jasmonic acid, and $\mathrm{d}_{4}$ salicylic acid (CDN Isotopes, Pointe-Claire, Quebec, Canada). Samples were vortexed then placed in an

11 ultrasonic ice bath for 30 minutes, then washed with dichloromethane and centrifuged at 13,200

$12 \mathrm{rpm}$ for 5 minutes. Nine-hundred microliters of the lower phase were taken and dried. Samples

13 were reconstituted in 100 microliters of $15 \%$ methanol and stored at $-20{ }^{\circ} \mathrm{C}$ until analysis.

Chromatographic separations were performed on an Agilent 1290 Infinity UHPLC with binary pump, autosampler, and temperature-controlled column compartment. Samples were

16 analyzed in multiple reaction mode using an Agilent (Santa Clara, CA, USA) 6460 triple

17 quadrupole mass spectrometer equipped with an Agilent Jetstream electrospray source. Instrument control and data acquisition was performed in Agilent Masshunter Acquisition (ver 7). Hormones were detected using the MRM transitions in Supplementary File S2. Hormones were quantified by internal standard after determining the linear regions for each.

A binary solvent system consisting of $10 \mathrm{mM}$ ammonium formate in water (mobile phase

22 A) and $10 \mathrm{mM}$ ammonium formate in acetonitrile (mobile phase B) was used for

23 chromatographic separations on an Agilent (Santa Clara, CA, USA) Poroshell 120 EC-C18 (150

$24 \times 2.1 \mathrm{~mm}, 2.7 \mu \mathrm{m})$ column fitted with a Poroshell guard column containing the same phase. The 25 mobile phase program used for separations was as follows: $0 \mathrm{~min}, 5 \% \mathrm{~B} ; 2 \mathrm{~min}, 5 \% \mathrm{~B} ; 6 \mathrm{~min}$, $2640 \% \mathrm{~B} ; 6.5 \mathrm{~min}, 100 \% \mathrm{~B} ; 8.5 \mathrm{~min}, 100 \% \mathrm{~B} ; 9.5 \mathrm{~min}, 5 \% \mathrm{~B}$. The column was allowed to

27 equilibrate for 6 minutes at starting conditions prior to the next injection. Flowrate for analyses was $0.4 \mathrm{~mL} / \mathrm{min}$, the column temperature was maintained at $35^{\circ} \mathrm{C}$, and an injection volume of

$2920 \mu \mathrm{L}$ was used for all samples. Source conditions for the Jetstream electrospray source were as 30 follows: Drying gas temperature $100{ }^{\circ} \mathrm{C}$, drying gas flow $8 \mathrm{~L} / \mathrm{min}$, sheath gas temperature 300 
$1{ }^{\circ} \mathrm{C}$, sheath gas flow $10 \mathrm{~L} / \mathrm{min}$, nebulizer 50 psi, capillary voltage $3500 \mathrm{~V}$ (both positive and

2 negative mode), and nozzle voltage $0 \mathrm{~V}$.

\section{Water-soluble metabolite extraction and LC-MS}

The same samples used for RNAseq and hormone analyses were used to measure watersoluble metabolites by LC-MS. Approximately two hundred milligrams (mean $202.12 \pm 4.87$ $\mathrm{mg}$ ), of berry powder were weighed while frozen. Extractions and analyses were randomized and

8 performed in technical duplicate. Hormones were extracted in $1 \mathrm{~mL} \mathrm{1 \%} \mathrm{HCl}$ in HPLC-grade $\mathrm{H}_{2} \mathrm{O}$ (prepared in-house, final resistance $18 \mathrm{M} \Omega, 0.2 \mu \mathrm{m}$ filtered) and spiked with salicin (Sigma Aldrich, St. Louis, MO, USA) as an internal standard (50 $\mu \mathrm{g} / \mathrm{L}$ final concentration). The samples were vortexed, placed in an ultrasonic ice bath for 30 minutes, and centrifuged. The supernatants were collected and frozen at $-80^{\circ} \mathrm{C}$ until analyzed.

Chromatographic separations were performed on an Agilent (Santa Clara, CA, USA) 1290 Infinity II UHPLC (equipped with a binary pump, multisampler, and temperaturecontrolled column compartment) that was connected to a 6545 Q-TOF MS. An Agilent 1260 isocratic pump was used for introduction of reference mass solution (constant flow of 0.8 $\mathrm{mL} / \mathrm{min}$ during analysis and split 1:100 prior to reference nebulizer). Chromatographic separations were performed using an Agilent Zorbax Eclipse Plus C18 (50x2.1 mm, $1.8 \mu \mathrm{m})$ column fitted with a guard column of the same stationary phase and kept at $50{ }^{\circ} \mathrm{C}$. All extracts were analyzed on an Agilent (Santa Clara, CA, USA) 6545 Q-TOF mass spectrometer equipped with a dual Jetstream electrospray source, once in positive mode and once in negative mode. Instrument control and data acquisition was performed in Agilent Masshunter Acquisition (ver 8). Prior to analysis, a low mass transmission tune was performed in both positive and negative ion modes following the Agilent guidelines. Data acquisition was performed in the MS only mode with a mass spectral range of $m / z$ 90-1000 and a scan rate of 4 spectra/sec. The Agilent All-ions workflow with collision energies of $0 \mathrm{~V}$ and $25 \mathrm{~V}$ was used to collect non-targeted

27 fragmentation data for compound identification.

A binary solvent system was used consisting of $1 \%$ formic acid in water (mobile phase A) and 1\% formic acid in acetonitrile (mobile phase B). The solvent program was as follows: $0.00 \mathrm{~min}, 3 \% \mathrm{~B} ; 4.67 \mathrm{~min}, 35 \% \mathrm{~B} ; 5.00 \mathrm{~min}, 80 \% \mathrm{~B}$; $6.67 \mathrm{~min}, 80 \% \mathrm{~B} ; 7 \mathrm{~min}, 3 \% \mathrm{~B}$. The

31 column was equilibrated at starting conditions for 3 minutes between injections and an injection 
1 volume of $4 \mu \mathrm{L}$ was used for all samples. Reference mass correction was performed using purine

2 and hexakis $(1 \mathrm{H}, 1 \mathrm{H}, 3 \mathrm{H}$-tetrafluoropropocy)phosphazene for both positive and negative modes.

3 Water soluble metabolites (Supplementary File S2) were analyzed by a targeted data analysis

4 method in Masshunter Quantitative Analysis (ver 10.1). Metabolites were identified by accurate

5 mass, retention time, and characteristic fragments from the $25 \mathrm{~V}$ collision energy channel.

6

7 Data visualization

$8 \quad$ Figures depicting quantitative data were built using the following R packages: ggplot2

9 (Wickham, 2016), hrbrthemes (Rudis, 2020), wesanderson (Ram and Wickham, 2018), pheatmap

10 (Kolde, 2019) and UpSetR (Gehlenborg, 2019). 


\section{Results}

2 GLRaV species and rootstock influence canopy density, cluster weight and fruit composition

A
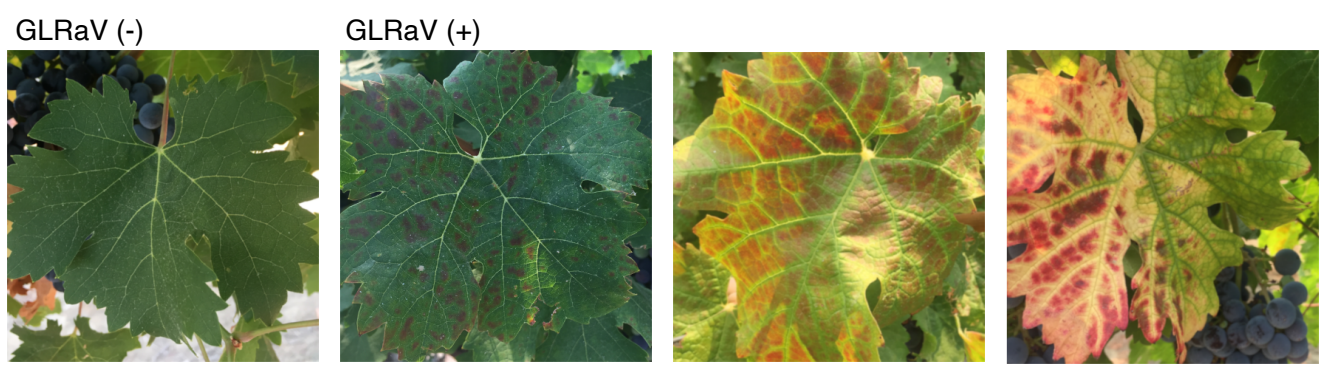

B $\operatorname{GLRaV}(-)$
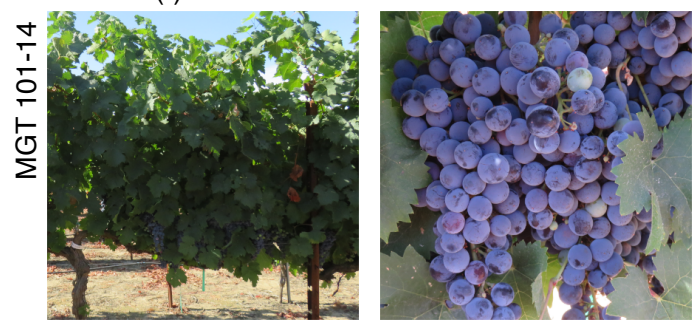

GLRaV-1,2 (+)
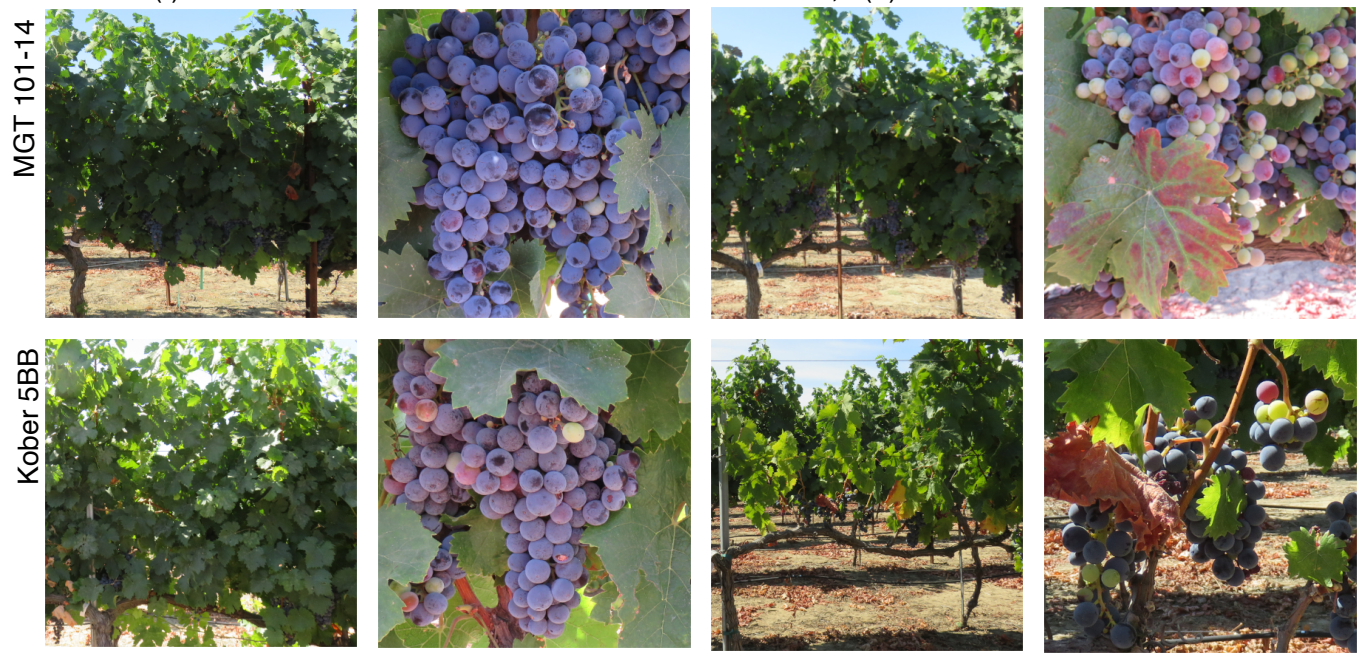

Figure 1. Effects of grapevine leafroll-associated viruses on Cabernet franc leaves, canopy density, and cluster size. (A) Leaves sampled slightly before (August 8) and at mid-ripening (August 13) in 2018 from GLRaV (-) and GLRaV (+) (B) Canopy and berry clusters from GLRaV (-) and GLRaV-1,2 (+) in different rootstock conditions on August 14, 2017.

The ways that individual and pairs of GLRaVs (GLRaV-1, GLRaV-3, GLRaV-4 strain 5,

9 GLRaV-1,2, and GLRaV-1,3) and rootstock (MGT 101-14 and Kober 5BB) combinations

10 influence grape berry ripening were studied in a dedicated experimental vineyard at the

11 University of California, Davis.

12 Typical grapevine leafroll disease symptoms (i.e., leaf-reddening and curling) were

13 observed by mid-ripening (Fig. 1A). In addition, there was a visible, stark reduction in canopy

14 density and cluster size in GLRaV-1,2 (+) versus GLRaV (-) in vines grafted to Kober 5BB that

15 was not readily apparent in vines grafted to MGT 101-14 with the same infection status (Fig.

16 1B). 

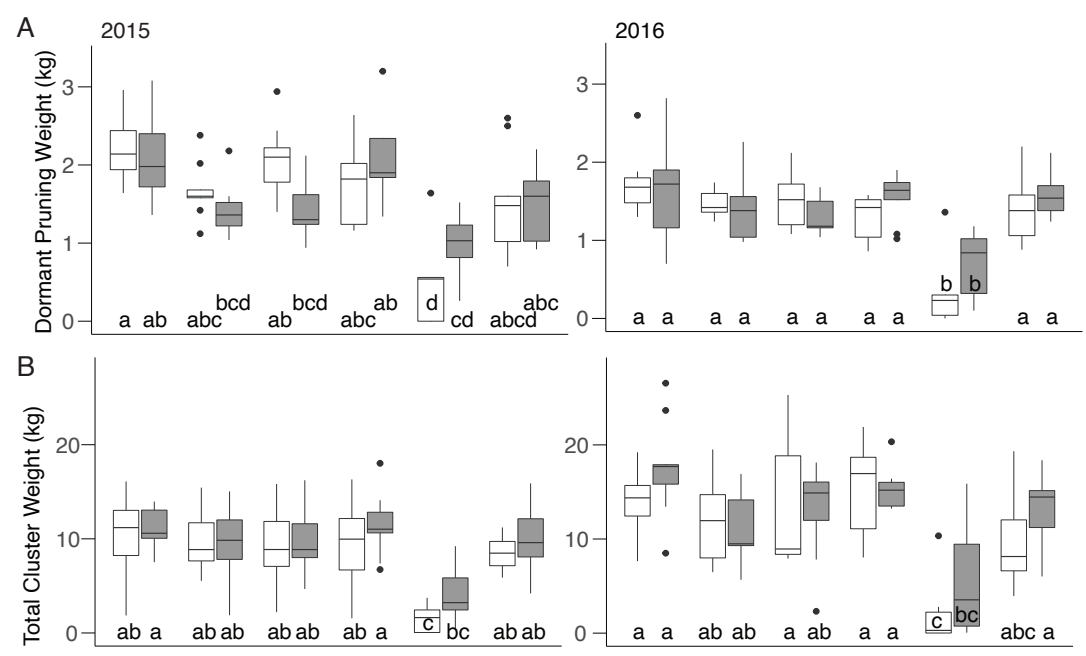

C
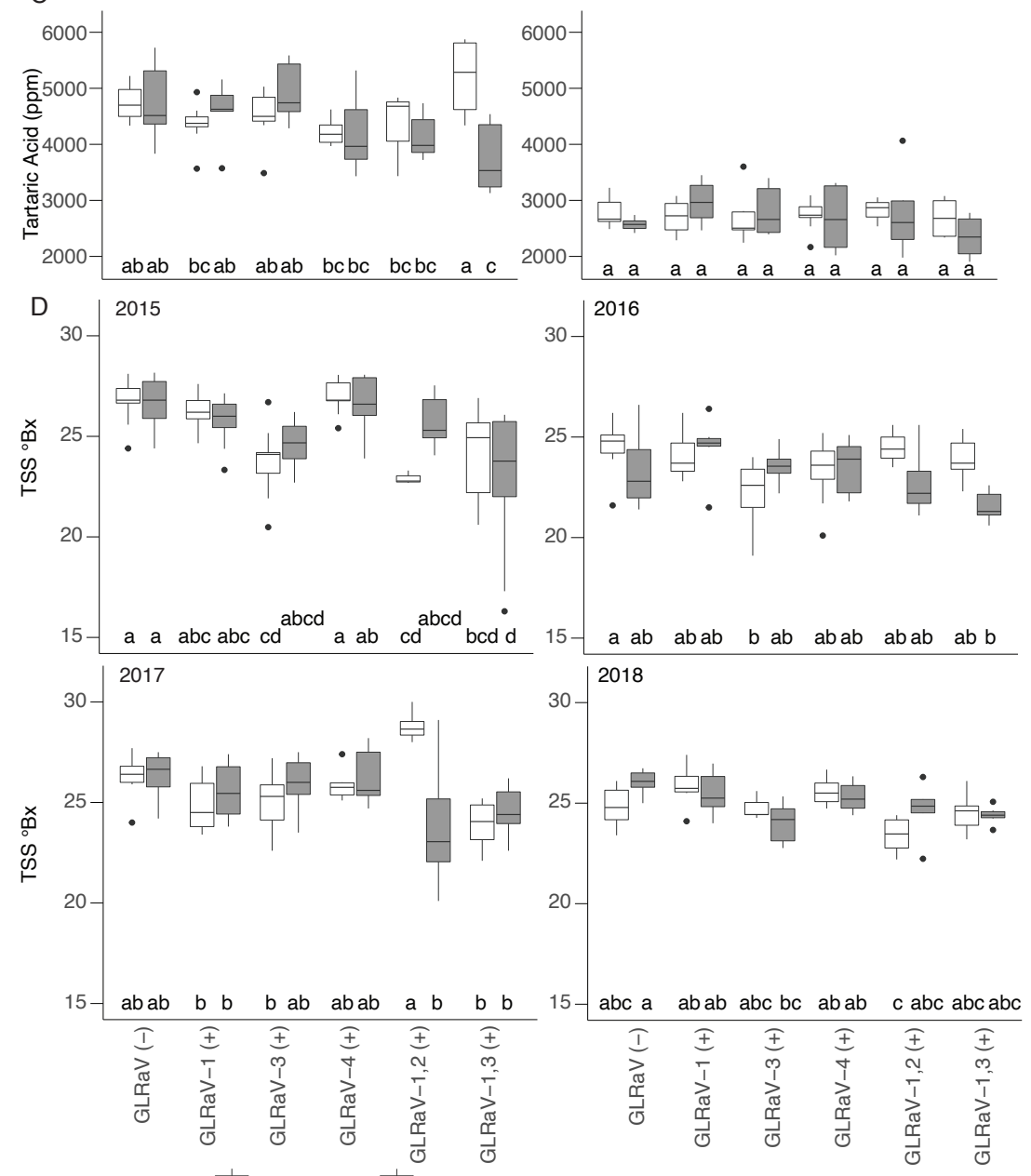

Roatstock $\biguplus_{1}$ Kober 5BB

Figure 2. Effects of GLRaV infection on (A) Dormant Pruning Weight, $5 \leq \mathrm{n} \leq 9$, (B) Total cluster weight, $5 \leq \mathrm{n} \leq 9$ and (C)

3 Tartaric acid, $3 \leq \mathrm{n} \leq 9$, in 2015 and 2016. No significant differences between groups were observed in tartaric acid in 2016. (D)

4 Total soluble solids at harvest in four consecutive years. 2015-2016, $5 \leq \mathrm{n} \leq 9 ; 2017-2018, \mathrm{n}=6$. Group differences are indicated

5 with non-overlapping letters (Tukey HSD, $\mathrm{P}<0.05$ ). 
Vine growth, cluster weight, and other measures were collected in 2015 and 2016 (Fig. 2,

2 Supplementary Fig. S3). The effect of GLRaV infection on dormant pruning weight, berry

3 weight, $\mathrm{pH}$, and tartaric acid in 2015 and on moisture content, total anthocyanin content, and

4 titratable acidity in 2016 differed significantly based on the rootstock present (ANOVA, P <

5 0.05). This interaction was significant for malic acid in 2015 and 2016. Significant differences in

6 dormant pruning weights, total cluster weights, and tartaric acid were observed in plants with

7 different GLRaV infection status and rootstock (Tukey HSD, P $<0.05$ ). In contrast, few or no

8 significant differences between $\mathrm{GLRaV}(+)$ given the same rootstock were observed for total

9 anthocyanins, moisture content, malic acid, $\mathrm{pH}$, titratable acidity, weight per berry, or yeast assimilable nitrogen and overwhelmingly in a single year if at all (Supplementary Fig. S3).

Overall, GLRaV infection tended to reduce dormant pruning weight and cluster weight.

12 The dormant pruning weights and cluster weights of GLRaV-1,2 (+) were significantly less than

13 GLRaV (-) and other GLRaV (+) (Fig. 2AB); this was observed for both rootstock conditions.

14 Significant differences in fruit tartaric acid levels were observed in only 2015 and were between

15 GLRaV-1,3 (+) grafted to different rootstocks and between plants with different GLRaV

16 infection status (Fig. 2C). In each year except 2015, there was a significant interaction between

17 rootstock and GLRaV infection status in terms of TSS at harvest (ANOVA, P $<0.05$, Figure

18 2D). This interaction was significant at each other developmental stage in 2017 and at prevéraison in 2018 (Supplementary Fig. S3). Significant differences in TSS at harvest were found between GLRaV (-) and GLRaV (+) in each year except 2017 (Fig. 2D). Overall, significant

21 reductions in TSS relative to GLRaV (-) were limited to the dual infections and GLRaV-3 (+).

22 Significant differences were observed between rootstocks in GLRaV 1,2 (+) at every

23 developmental stage, albeit only in 2017 (Fig. 2D, Supplementary Fig. S3).

These data provide limited evidence that (1) different GLRaVs may or may not affect various aspects of vine growth and fruit composition, (2) that some of these differences are rootstock-specific, and (3) that although some of these effects are observed across years, year-to-

27 year differences may impact whether or not effects occur. 
bioRxiv preprint doi: https://doi.org/10.1101/2021.03.14.434319; this version posted March 15, 2021. The copyright holder for this preprint (which was not certified by peer review) is the author/funder. All rights reserved. No reuse allowed without permission.

1 GLRaVs elicit reproducible changes in gene expression across infection types and rootstocks

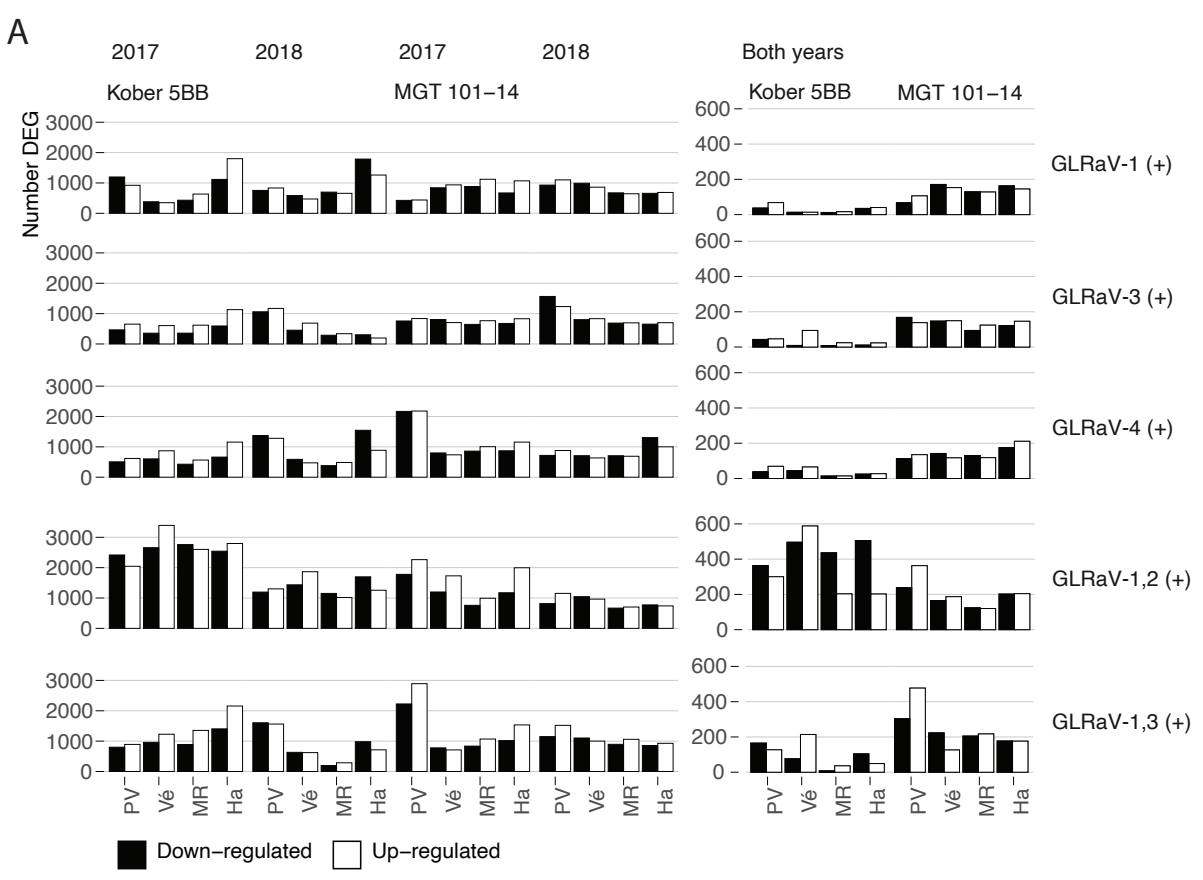

B

Pre-véraison Véraison Mid-ripening Harvest

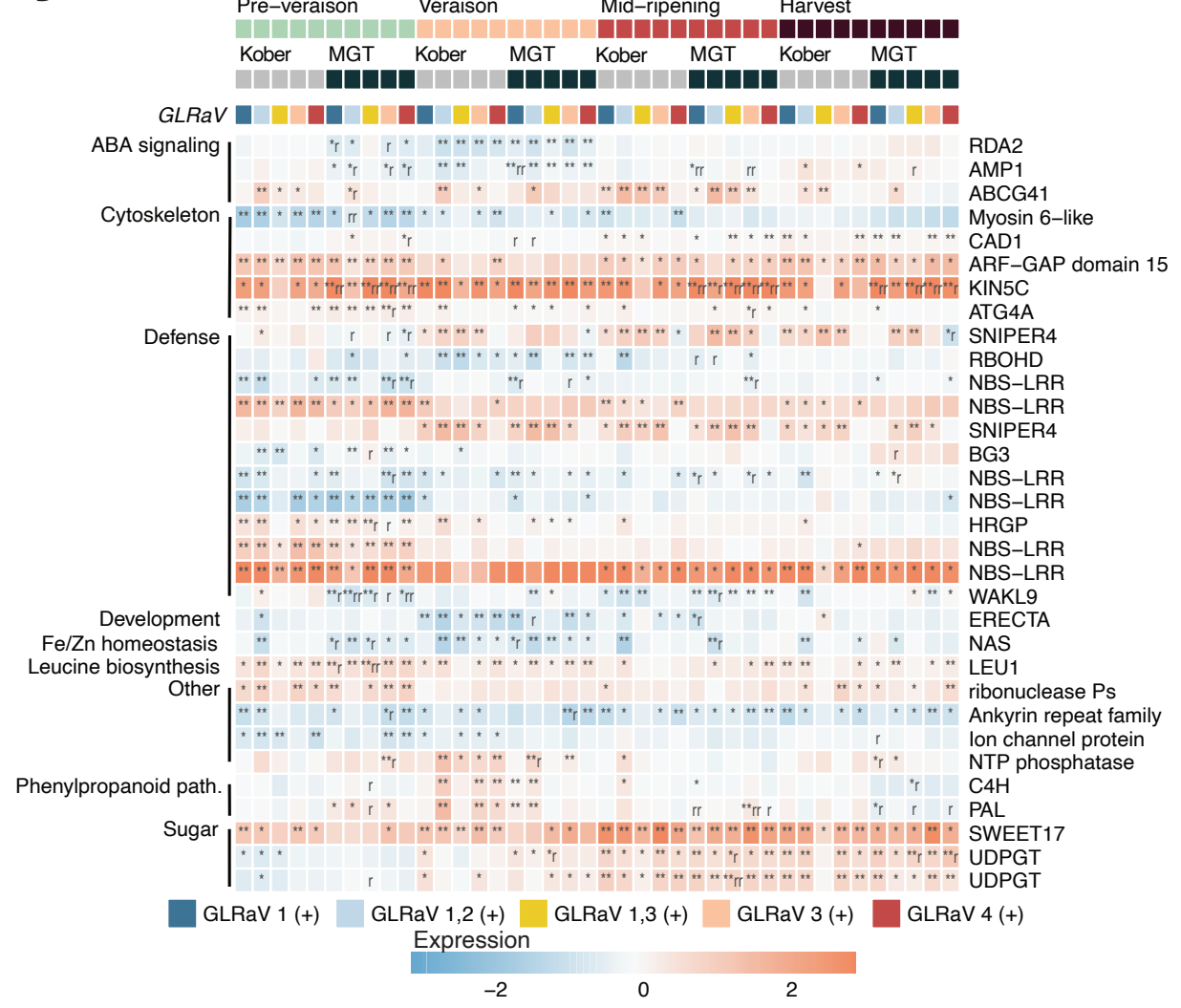

Figure 3. Differentially expressed genes in GLRaV-infected grapevines. (A) Barplots showing the number of differentially

4 expressed $(\mathrm{P}<0.05)$ genes up and down-regulated in GLRaV $(+)$ versus GLRaV $(-)$ in berries from Cabernet franc grapevines 
grafted to different rootstocks (Kober 5BB, Kober; MGT 101-14, MGT) at each developmental stage (Pre-véraison, PV;

Véraison, Vé; Mid-ripening, MR; Harvest, Ha) in each year and in both years. (B) Conserved responses to GLRaVs (P < 0.05) observed in both rootstock conditions and in more than one GLRaV $(+)$ condition. One asterisk, differentially expressed in one year; Two asterisks, differentially expressed in both years. One or two "r", the effects of a particular GLRaV infection differ between rootstocks at the same developmental stage. Any notation requires the direction (up/down-regulation) of the effect to be consistent in both years, even if a significant change occurred in only a single year.

We used RNAseq to sequence the transcriptome of 384 Cabernet franc berry samples collected from plants grafted to different rootstocks (Kober 5BB or MGT 101-14), with different GLRaV infection status (GLRaV (-), GLRaV-1 (+), GLRaV-3 (+), GLRaV-4 (+), GLRaV-1,2 $(+)$ or GLRaV-1,3 (+)), at four developmental stages (pre-véraison, véraison, mid-ripening, and harvest), and in two consecutive years (2017 and 2018).

Because of the remarkable structural and gene content variability among grape cultivars (Da Silva et al., 2013; Venturini et al., 2013; Minio et al., 2019), we built a genome reference specifically for the analysis of these RNAseq data. The genome was assembled into 504 primary contigs $(\mathrm{N} 50=5.74 \mathrm{Mbp})$ for a total assembly size of $570 \mathrm{Mbp}$. This is comparable to the size of the Zinfandel (591 Mbp; (Vondras et al., 2019)), Cabernet Sauvignon (590 Mbp; (Chin et al., 2016)), Chardonnay (490 Mb; (Roach et al., 2018)) and Pinot noir PN40024 (487 Mb; (Jaillon et al., 2007)) genomes. Three thousand eighty-five additional haplotigs were assembled with an N50 of 184 kbp (Supplementary Table S4). The primary assembly and haplotigs were annotated with 33,563 and 19,146 protein-coding genes, respectively (Supplementary Table S4).

Ripening was associated with transcriptomically distinct developmental stages. Samples clustered primarily by developmental stage and secondarily by year, though samples at harvest clustered separately (Supplementary Fig. S5). Genes with comparable, significant responses (consistently up-regulated or down-regulated, $\mathrm{P}<0.05$ ) in both years of the study were selected to identify reproducible responses to GLRaVs during ripening. Gene expression in GLRaV (+) was compared to gene expression in GLRaV (-) grafted to the same rootstock at the same developmental stage (Fig. 3A). In addition, the effects of each GLRaV infection on gene expression at each developmental stage were compared in plants grafted to different rootstocks (Supplementary Fig. S6).

On average, $7.1 \%$ of the genes differentially expressed between GLRaV (-) and GLRaV $(+)$ were reproduced in both years (Fig. 3A). This percentage was slightly above average for plants with dual, relatively more severe, infections $(8.6 \%$, GLRaV-1,3 (+); 8.9\%, GLRaV-1,2 
$1(+))$ and below average for individual infections $(5.8 \%, \mathrm{GLRaV}-1(+) ; 6 \% \mathrm{GLRaV}-4(+) ; 6.2 \%$

2 GLRaV-3 (+)). A subset of 32 genes significantly changed their expression level in two or more

$3 \mathrm{GLRaV}(+)$ infection conditions, in both rootstock conditions, and at least one developmental

4 stage (Fig. 3B). These genes constitute the "conserved" responses to GLRaVs in Cabernet franc

5 berries during ripening.

The majority of these are associated with defense, ABA signaling, and cytoskeleton organization and biogenesis (Fig. 3B; Supplementary File S7). Six of these were nucleotide-

8 binding site and leucine-rich repeat-containing (NBS-LRR) genes; half of these were upregulated. Two F-box genes encoding SNIPER4 were up-regulated (Huang et al., 2018), as was a gene encoding a hydroxyproline-rich glycoprotein (HRGP). HRGP and NBS-LRR proteins are associated with pathogen detection (DeYoung \& Innes, 2006). Genes encoding a respiratory burst oxidase protein D (RBOHD), a wall-associated kinase-like protein (WAKL), and a betaglucosidase 3 (BG3) were down-regulated. RBOHD participates in the production of reactive oxygen species (ROS) and hypersensitive responses to pathogens (Otulak-Kozieł et al., 2019). RBOH family proteins are targeted by Snf1-related kinase 2 (SnRK2) phosphorylation, a key component of the ABA signaling pathway. Likewise, a $W A K L$ gene in citrus participates in

17 jasmonic acid and ROS signaling (Li et al., 2020). Among the functions of BGs are the activation of ABA and SA by freeing them from the conjugates that render them inactive (Seo et al., 1995; Morant et al., 2008; Zhang et al., 2012; Sun et al., 2014; Jia et al., 2016). Several ABA-related genes were among the conserved GLRaV responses, including an up-regulated $\mathrm{ABC}$ transporter and two down-regulated genes, $A M P 1$ and $R D A 2$. AMP1 negatively regulates ABA sensitivity (Shi et al., 2013). RDA2 participates in the inhibition of ABA signaling and the promotion of MAPK signaling (Park et al., 2019).

There were five genes related to the cytoskeleton sensitive to GLRaV infection. Only one of these, a myosin VI motor protein coding gene, was down-regulated. The four others were autophagy genes (ATG) $4 A$ and constitutively activated cell death 1 (CAD1), which function in

27 autophagy, lytic pore formation, and hypersensitive response (Yoshimoto et al., 2004; Morita28 Yamamuro et al., 2005; Haxim et al.), Kinesin-like 5C (KIN5C), which encodes a microtubule motor protein (Reddy \& Day, 2001), and an ADP-ribosylation factor GTPase-activating protein

$30(A R F-G A P)$ domain 15, which helps efficiently load vesicles and remodel the actin cytoskeleton 31 (Inoue \& Randazzo, 2007). 
Several additional general functional categories were present among the 32 genes that

2 exhibited conserved responses to GLRaVs (Fig. 3B). Genes encoding phenylalanine ammonia-

3 lyase $(\mathrm{PAL})$ and cinnamate 4-hydroxylase $(\mathrm{C} 4 \mathrm{H})$, which catalyze the first two steps of the

4 phenylpropanoid pathway, two genes encoding UDP glucosyltransferases (UDPGT), which

5 conjugate sugars, and SWEET17, a sugar transporter, were up-regulated, as was a gene encoding

6 3-isopropylmalate dehydratase, an enzyme in the leucine biosynthetic pathway. Two genes,

7 encoding a leucine-rich repeat receptor-like kinase (LRR-RLK) called ERECTA and

8 nicotianamine synthase (NAS), were down-regulated. ERECTA participates in organ

9 development and resistance to bacterial and fungal pathogens (Goff \& Ramonell, 2007). NAS

10 expression increases Fe and Zn abundance in rice (Moreno-Moyano et al., 2016; Nozoye, 2018).

11 Generally, these genes and their changes in expression suggest that a common response

12 to GLRaVs in Cabernet franc berries during ripening includes the modulation of pathogen

13 detecting genes, an increase in ABA transport and signaling, a decrease in ROS-related

14 signaling, and an enhancement of cytoskeleton remodeling, vesicle trafficking, phenylpropanoid

15 metabolism, sugar transport and conjugation, and leucine biosynthesis.

17 Rootstock influences the impact of GLRaV on abscisic acid metabolism

18 The same berry samples used for RNAseq were used to measure three hormones associated with ripening and/or stress, including SA, JA, and ABA, and additional metabolites,

20 including xanthoxin, a precursor to ABA, and ABA glucose ester (ABA-GE), a conjugate of

21 ABA implicated in its long-distance transport (Jiang \& Hartung, 2008). The mean levels of SA

22 and JA were significantly influenced by year and/or by interactions between year, rootstock, and

23 GLRaV at pre-véraison (ANOVA, P < 0.05), but no significant differences were observed

24 between individual groups (Tukey HSD, P > 0.05) (Supplementary File S8). In contrast, year

25 alone had a significant impact on the levels of ABA and related metabolites measured at each

26 developmental stage, but largely did not interact with rootstock or GLRaV infection type to

27 affect the abundance of ABA and related metabolites (Supplementary File S8). In addition, the

28 effect of GLRaV infection on ABA and ABA-GE content significantly differed based on

29 rootstock (Supplementary File S8). Significant differences in ABA and ABA-GE content were

30 observed between rootstocks in plants with identical infection status and between plants with 
1 different GLRaV status grafted to the same rootstock (Tukey HSD, P < 0.05). Such differences

2 were scarcely observed for xanthoxin, a precursor to ABA (Fig. 4A, Supplementary File S8).

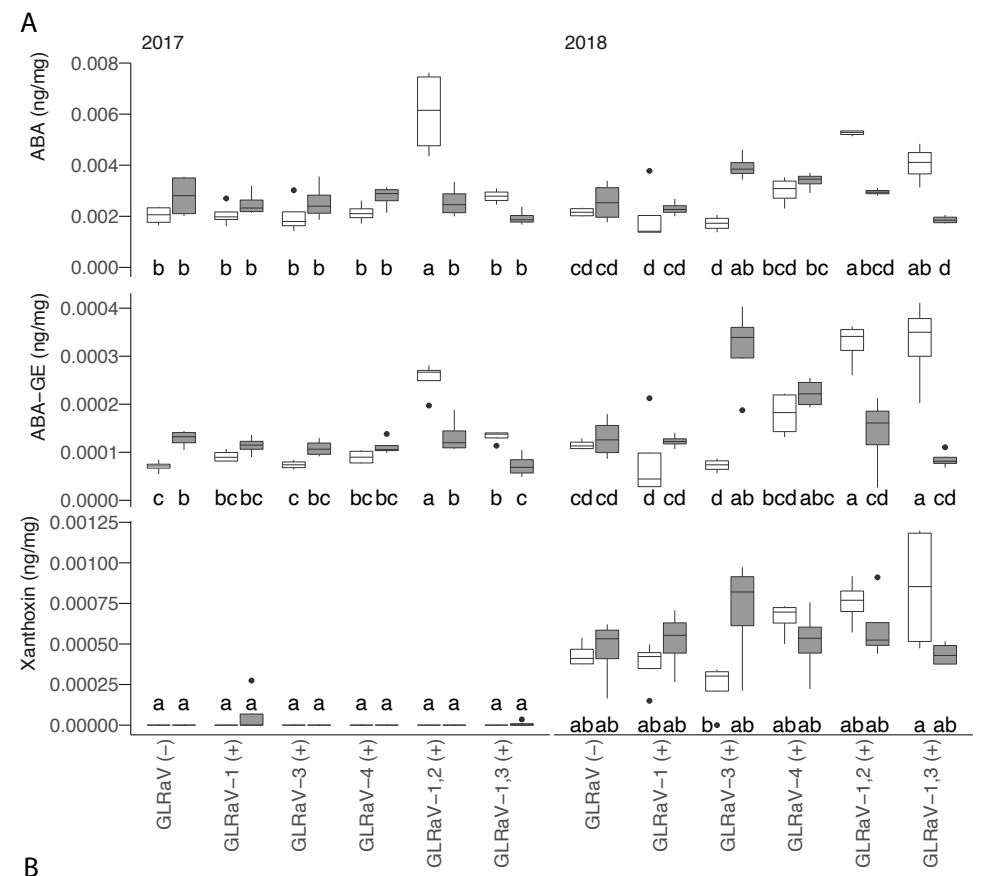

B

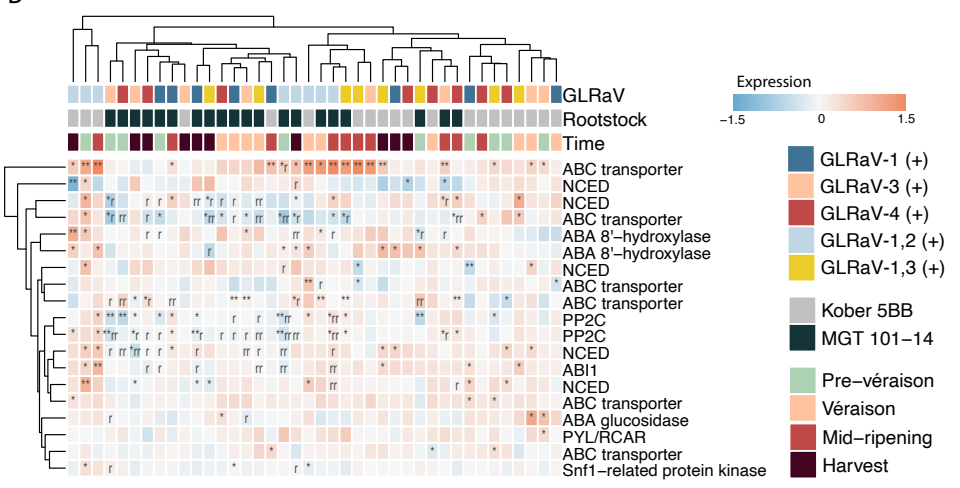

Figure 4. (A) Abundance of ABA, ABA-GE, and xanthoxin in 2017 and 2018 at pre-véraison. Groups with non-overlapping letters are significantly different (Tukey HSD, $\mathrm{P}<0.05$ ). (B) The effect of GLRaV infection(s) and rootstock on ABA biosynthetic and signaling genes. One asterisk, differentially expressed in one year; Two asterisks, differentially expressed in both years. One or two "r", the effects of a particular GLRaV infection differs between rootstocks at the same developmental

8 stage. Any notation requires the direction (up/down-regulation) of the effect to be consistent in both years, even if a significant change occurred in only a single year.

In the course of development, significant differences in the abundance of these

12 metabolites between rootstock conditions were observed most at pre-véraison and in GLRaV (-),

13 GLRaV-3 (+), and dual infections (Fig. 4A, Supplementary File S8). In GLRaV (-) and most

14 single infection conditions, the level of all three metabolites tended to be higher in berries from 
1 plants grafted to MGT 101-14 than in berries from plants grafted to Kober 5BB. The opposite

2 tended to be true when two GLRaVs were present. With one exception, significant changes in

3 the abundance of ABA and ABA-GE in GLRaV (+) versus GLRaV (-) were typically increases

4 and most often observed in berries from Kober 5BB-grafted plants (Tukey HSD, P $<0.05$ ).

5 Though slight reductions in these metabolites were often observed versus GLRaV (-), these were

6 almost always non-significant.

$7 \quad$ We further investigated abscisic acid biosynthesis and signaling using a previously

8 published, curated set of genes (Pilati et al., 2017). Their expression largely clustered according

9 to rootstock, with some exceptions; Kober 5BB GLRaV-1,2 (+), for example, tended to cluster

10 separately from other Kober 5BB-grafted plants. Nonetheless, the effects of GLRaVs differed

11 between rootstocks for many of these genes (Fig. 4B). One of these, an ABC transporter

12 (VITVvi_vCabFran04_v1_P438.ver1.0.g381930), is also included in Figure 3; significant

13 increases in its expression were observed in both years, in both rootstock conditions, and for

14 several GLRaV infections. All other significant changes in GLRaV (+) vs. GLRaV (-) that were

15 reproduced in both years occurred in only one rootstock or the other. These changes were sparse.

16 However, significant differences between rootstocks in identical GLRaV $(+)$ were reproduced in

17 both years for 9 out of these 19 genes. Significant differences between rootstocks in at least one

18 year were observed for 16 out of these 19 genes. On average, three of the 9-cis-epoxycarotenoid

19 dioxygenases (NCEDs), both ABA 8' hydroxylases, three ABC transporter genes, one gene

20 encoding PP2C, and PYL/RCAR were up-regulated in berries from plants infected with GLRaV

21 in both rootstock conditions. One ABC transporter gene was down-regulated in both rootstock

22 conditions. Of the remaining eight genes, most were down-regulated across development only in

23 berries from MGT 101-14-grafted plants.

25 Gene expression, hormone, and other metabolite data distinguish the effects of GLRaVs in

26 different rootstocks

27 Differential expression analysis identified 1,809 genes that (1) were differentially

28 expressed $(\mathrm{P}<0.05)$ in at least one year, $(2)$ in only one rootstock and more than one GLRaV

29 infection type versus GLRaV (-) and/or (3) the effects of more than one GLRaV infection

30 significantly differed between rootstocks (Supplementary Fig. S9). RNAseq, hormone, and

31 metabolite data from ripening Cabernet franc berries were integrated in a multiple factor analysis 
1 (MFA) to relate these variables and distinguish the effects of GLRaVs given different rootstocks 2 (Fig. 5, Supplementary Fig. S10, Supplementary Table S11).

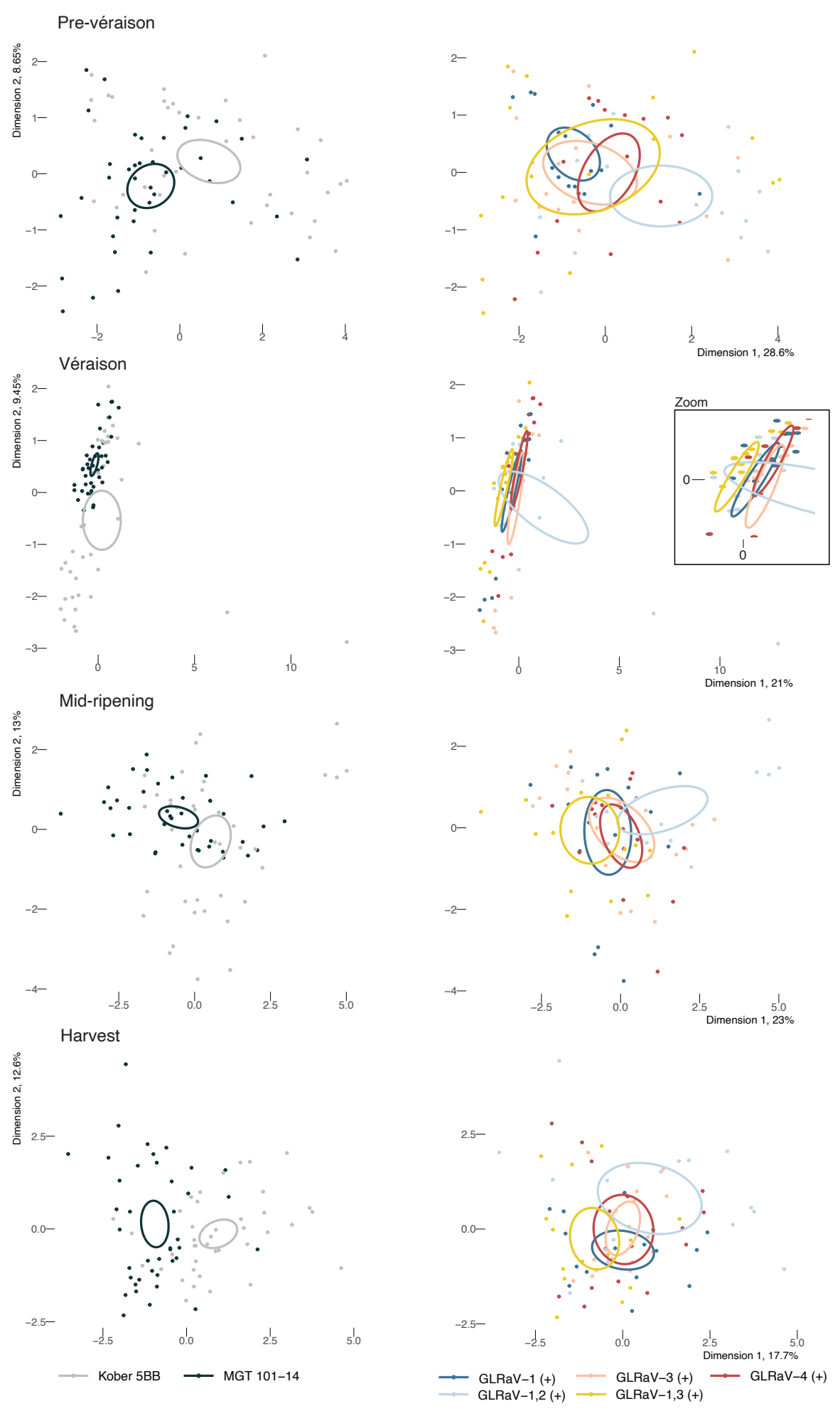

Figure 5. MFA of GLRaV (+) effects. Sample distribution along first two dimensions at each developmental stage. 95\%

5 Confidence ellipses are drawn for rootstocks (left) and GLRaV (+) conditions (right). 
As input for the MFA, all genes differentially expressed between GLRaV (-) and GLRaV

$2(+)$ or between rootstocks were used, plus all hormones and metabolites measured. Overall, the rootstocks were distinct at each developmental stage (Fig. 5). Some of the GLRaV (+) conditions

4 could be distinguished from others at pre-véraison, véraison, and harvest. At pre-véraison,

5 GLRaV-1,2 (+) differed overall from GLRaV-1 (+). At véraison, GLRaV-1,3 (+) differed from every other GLRaV $(+)$ condition except GLRaV-1,2 (+). At harvest, the two dual infections were different than one another and GLRaV-1,2 (+) differed from GLRaV-1 (+) (Fig. 5).

Next, we identified which variables were best correlated with each rootstockmetabolites were correlated with at least one of the first two MFA dimensions (Fig. 6A). The rootstock-dependent disparity in ABA and ABA-related genes (Fig. 4) is consistent with the observation that $\mathrm{ABA}$ and related metabolites tended to be highly correlated with rootstockdifferentiating MFA dimensions over time and that ripening initiates earliest in Kober 5BB plants with dual infections in terms of TSS (Supplementary Fig. S3).

There were 548 genes that shared high correlation $(\mid$ corr $\mid>0.5)$ to rootstockdifferentiating MFA dimensions with hormones or hormone-related metabolites. Most of these genes had shared positive or negative correlations to the same dimensions as ABA, xanthoxin, and/or ABA-GE (Fig. 6B). Genes with functionally relevant relationships to each hormone or hormone-related metabolite were overrepresented (Hypergeometric test, $\mathrm{P}<0.05$ and $\mathrm{n}>1$ gene) among the genes that shared high correlation to rootstock-differentiating MFA dimensions with each hormone. Genes with functional categories related to ABA signaling, starch biosynthesis catabolism, and in the C2C2-DOF transcription factor family were overrepresented among the genes correlated to the same dimensions as ABA and xanthoxin. The latter two categories were significantly overrepresented among the genes correlated with the same dimensions as ABA-GE. Genes related to heat shock protein (HSP) mediated protein folding, chaperone-mediated protein folding, cation channel-forming Heat Shock Protein-70, channels and pores, the reductive carboxylate cycle, and carbon fixation were overrepresented among those correlated with the same MFA dimensions as SA. Similarly, the abundance of most ripening-related metabolites measured were correlated with the same MFA dimensions as ABA, xanthoxin, and/or ABA-GE (Fig. 6C). 


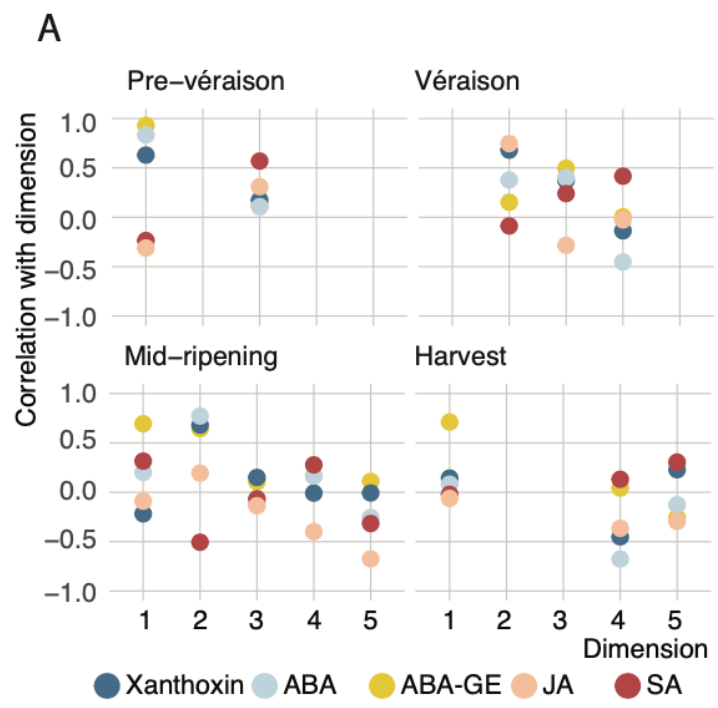

B

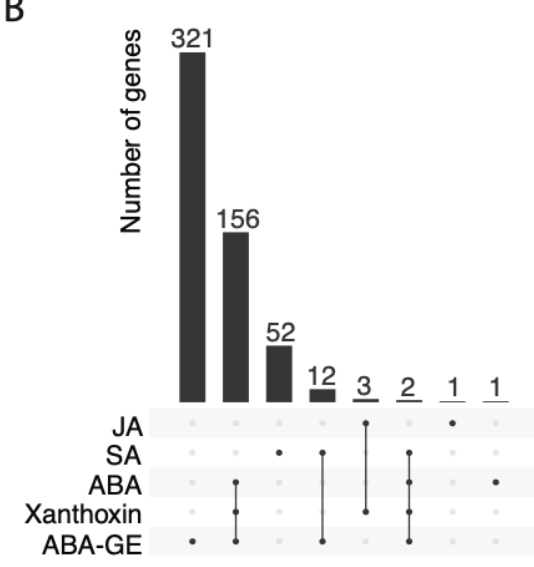

C

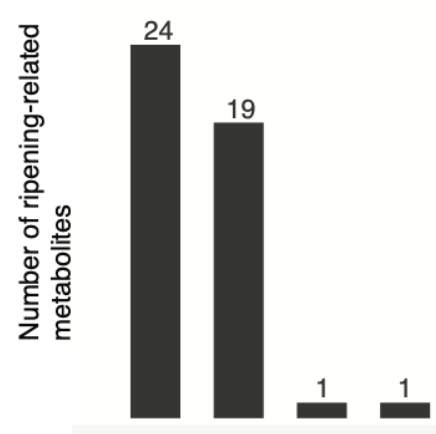

1

2 Figure 6. The role of genes, hormones, and metabolites in MFA of GLRaV effects. (A) Correlation between hormones and

3 closely related metabolites to rootstock-differentiating MFA dimensions. (B) Relationship between genes and hormones, and (C)

4 metabolites and hormones along rootstock-differentiating MFA dimensions. Shown are counts of genes and metabolites

5 correlated to the same dimensions as individual or groups of hormones or hormone-related metabolites. 
Overall, the effects of GLRaVs differ between rootstocks primarily in terms of ABA and

2 related metabolites. This finding is especially salient because of the role that ABA plays as a

3 ripening promoter near véraison, in root-scion communication, and plant stress. ABA,

4 metabolites, and genes that were well-correlated to rootstock-differentiating MFA dimensions

5 and were differentially expressed were scrutinized more closely.

Rootstock influences the impact of GLRaV on hormone signaling genes and transcriptional

8 controls.

There were 548 genes in 85 functional categories that were well-correlated with rootstock-differentiating MFA dimensions and differentially expressed between GLRaV (+)

11 grafted to different rootstocks or in GLRaV (+) versus GLRaV (-) in only one rootstock

12 condition (Fig. 7). These functional categories were generally related to hormone and other types

13 of signaling, amino acid and other metabolism pathways, transcription factors, transport, and

14 cellular organization and biogenesis (Fig. 7). Most of these genes coincided with ABA and

15 related metabolites along rootstock-differentiating MFA dimensions (Fig. 7).

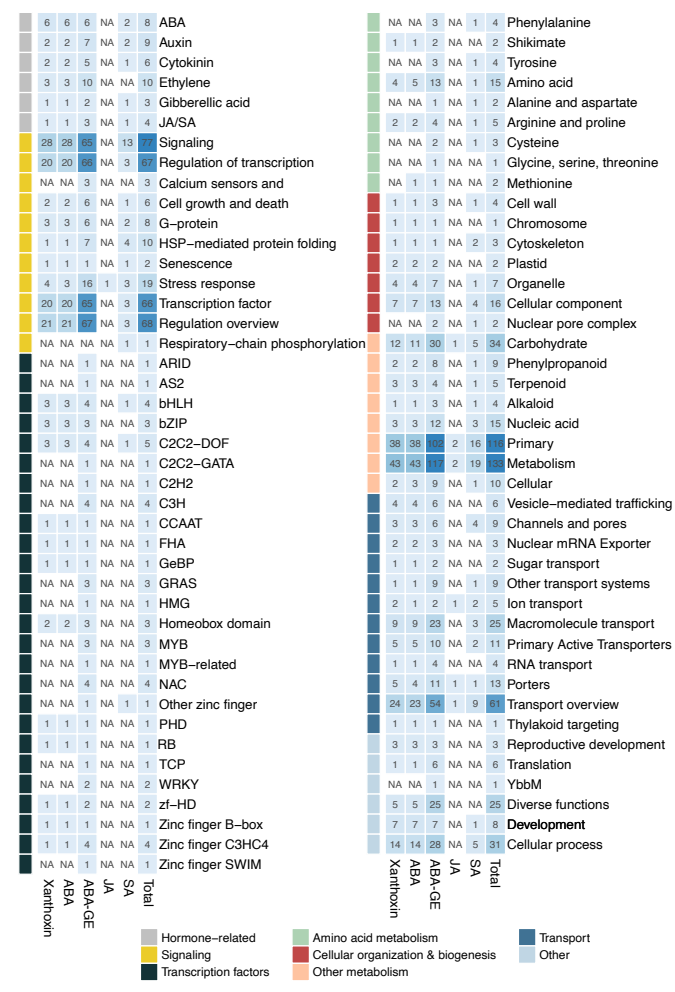

17 Figure 7. Functional categories of genes correlated to the same rootstock-differentiating MFA dimensions as hormones and 18 hormone-related metabolites. The counts of genes related to each hormone (shared high positive or negative correlation to 19 dimension, $(|\operatorname{corr}|>0.5)$ in each category are shown. 
The distribution of expression for four transcription factor families differed significantly between rootstocks at all four developmental stages (Supplementary Fig. S12, Kolmogorov

4 Smirnov, $\mathrm{P}<0.05)$. This included bHLH, C2C2-DOF, FHA, and homeobox domain

5 transcription factors. The distribution of expression for 39 hormone signaling-related genes differed significantly between rootstocks (Fig. 7, Supplementary Fig. S12, Supplementary File S13, Kolmogorov Smirnov, $\mathrm{P}<0.05)$. This was true at each developmental stage for ABA, 8 gibberellin (GA), and auxin signaling genes and at three developmental stages for JA/SA, cytokinin (CK), and ethylene signaling genes (Supplementary Fig. S12). Genes related to all of these hormone families had similar roles in MFA and were associated with ABA, including the JA/SA signaling genes (Fig. 7). This may reflect interactions between hormone signaling pathways. In addition, the effects of GLRaV infections (dual infections and GLRaV-4 (+)) on histone H1 expression were not equal in plants grafted to both rootstocks (Supplementary Fig. S14). Linker histone H1 contributes to higher-order chromatin structure (Hill, 2001). There were seven ABA signaling pathway genes (excluding VITVvi_vCabFran04_v1_P495.ver1.0.g468110, which was also associated with GA signaling)

17 that differentiated GLRaV effects in plants grafted to different rootstocks (Fig. 8). The mean

18 level of expression for all of these was higher in Kober 5BB than MGT 101-14 (Supplementary Fig. S12 ). This included $S O S 2, K E G$, three $P P 2 C(H A B 1, A H G 3, D B P)$ genes, and genes encoding two ABA-responsive element-binding proteins (AREB2, ABI5). SOS2 is a kinase appreciated for its role in salt stress response, seed germination, GA signaling (Trupkin et al.)

22 and in ABA signal transduction via its interaction with ABI2 and ABI5 (Ji et al., 2013; Zhou et $a l ., 2015)$. SOS2 was up-regulated in both rootstock conditions before and at véraison and down-

24 regulated after véraison. KEG is a negative regulator of ABA signaling; it maintains low levels of ABI5 in the absence of stress by ubiquitination and degradation (Stone et al., 2006; Lyzenga et al., 2013) and helps regulate endocytic trafficking and the formation of signaling complexes

27 on vesicles during stress (Gu \& Innes, 2011). KEG was down-regulated in Kober 5BB and down-regulated in MGT 101-14 at véraison and mid-ripening.

In the presence of $\mathrm{ABA}, \mathrm{ABA}$ receptors (PYR/PYL/RCAR family proteins) bind PP2Cs

30 like $\mathrm{HAB} 1$ and $\mathrm{AHG} 3$ to inhibit their phosphatase activity. As a result, ABA signal transduction

31 is permitted via SnRK2 phosphorylation of ABA-responsive element-binding proteins 
1 (Hirayama \& Shinozaki, 2010). ABI5 and AREB2 are bZIP transcription factors that bind to

2 ABA responsive elements (ABREs) to drive ABA signaling and ABI5 can integrate signals

3 across hormone signaling pathways (Skubacz et al., 2016). The effects of GLRaVs on these

4 genes in Kober 5BB were consistent with an enhancement of ABA signaling during ripening. In

5 Kober 5BB, HAB1 and AHG3 were down-regulated, and AREB2 and ABI5 were up-regulated.

6 In MGT 101-14, the PP2Cs were down-regulated for at least two developmental stages; AREB2

7 and ABI5 were up-regulated at and after véraison.
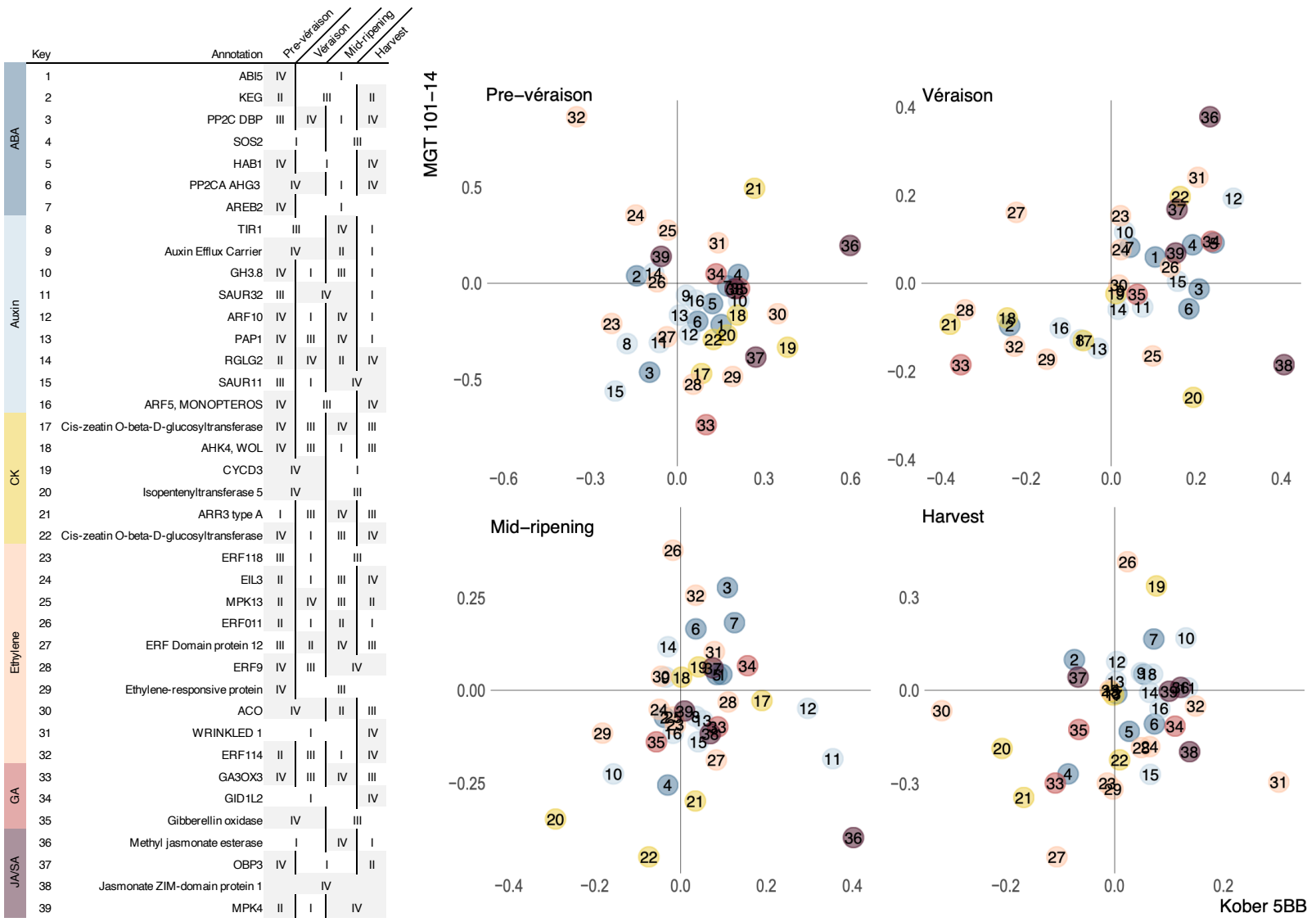

9 Figure 8. The effect of GLRaVs on hormone signaling gene expression in grape berries from plants grafted to different rootstocks. Quadrants are numbered counterclockwise from top right (I) to bottom right (IV). Individual genes are numbered 139. In addition to analyzing hormone and hormone-related metabolites, we analyzed

15 metabolites associated with the shikimate, phenylpropanoid and flavonoid pathways (Fig. 9AB) 16 and their biosynthetic and regulatory genes (Fig. 9C) in Cabernet franc berries during ripening 17 (Supplementary Fig. S15). Significant differences in expression versus GLRaV (-) were detected, 
1 as well as significant differences in the effects of GLRaV infection between different rootstock

2 conditions (Fig. 9C). The effects of GLRaV infection on the genes associated with this pathway

3 were generally consistent with the change in abundance of corresponding metabolites (Fig. 9B).

4 Overall, these genes tended to be up-regulated in GLRaV (+) at véraison (Fig. 9C). After

5 véraison, the amount of up-regulation tended to decrease, or genes were down-regulated (Fig.

6 9C). The three amino acids examined (phenylalanine, tryptophan, and tyrosine) tended to be less

7 abundant in GLRaV (+) across the developmental stages and the largest decreases were observed

8 at harvest (Fig. 9B). Mixed effects of GLRaVs were observed on the abundance of

9 hydroxycinnamic acids (caftaric and coutaric acid), $t$-resveratrol, and anthocyanins. Significant

10 changes versus GLRaV (-) tended to occur in only one year. During ripening, these were

11 significantly more abundant in Kober 5BB GLRaV-1,2 (+), Kober 5BB GLRaV-5 (+), and/or

12 MGT 101-13 GLRaV-3 (+) (Fig. 9B). Significant decreases were observed for GLRaV-1 (+) and

13 GLRaV-1,3 (+). Though non-significant, the size of the downward effect of some GLRaV

14 infections on these metabolites was tended to increase towards harvest. Finally, flavanols

15 (epigallocatechin and catechin) and flavonol (quercetin) glycosides tended to be elevated in

16 GLRaV (+) (Fig. 9B). The size of this effect tended to be greatest before and at véraison and

17 decreased towards harvest. Significant differences between rootstocks were observed for

18 GLRaV-1,2 (+) in both years and for GLRaV-1 (+), GLRaV-1,3 (+), and GLRaV-3 (+) in

19 individual years; the increase in flavonols and flavanols tended to be greater in berries from

20 Kober 5BB GLRaV (+) than MGT 101-14 GLRaV (+). 


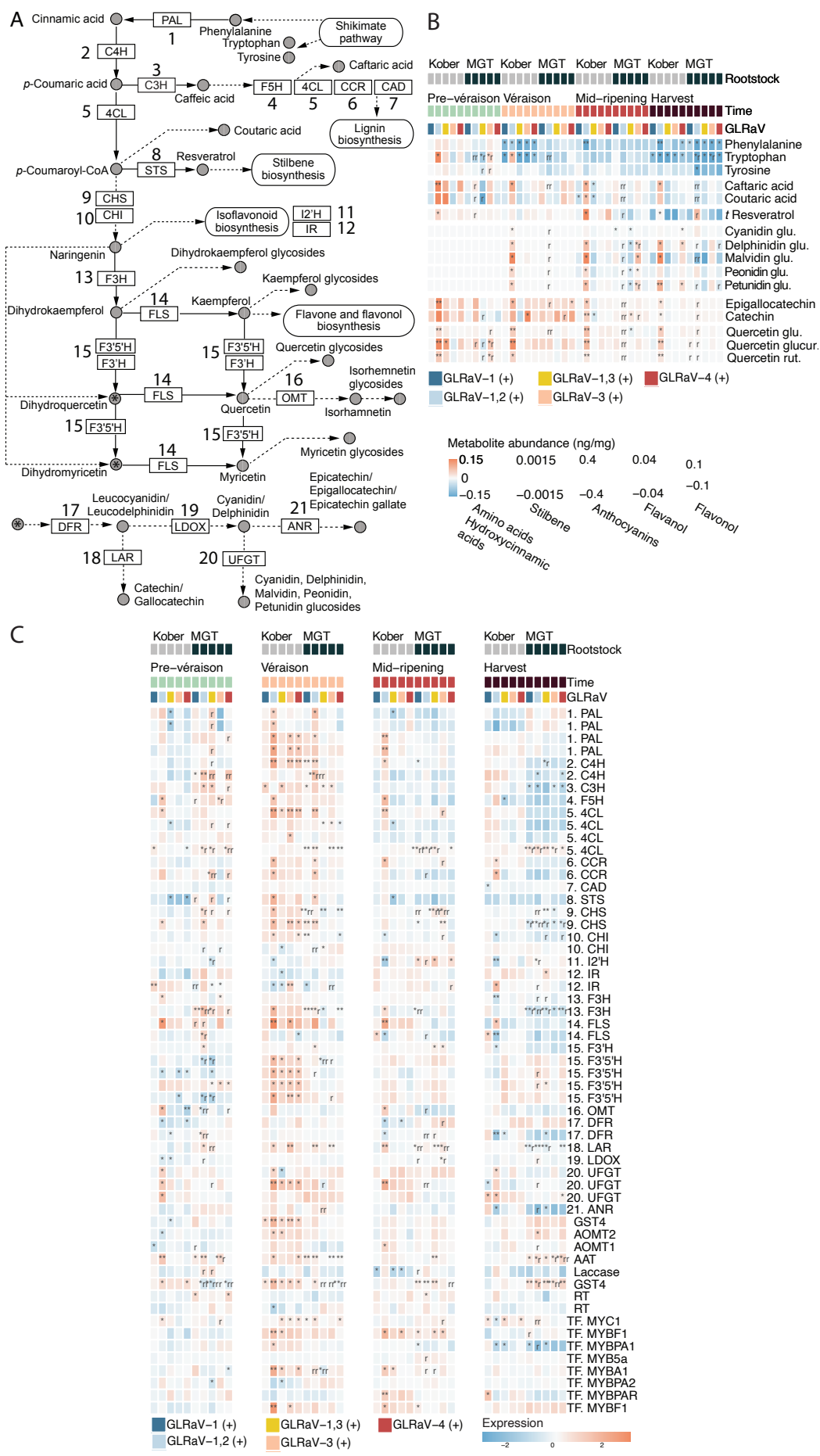

2 Figure 9. Differentially expressed genes and selected metabolites products of the shikimate, phenylpropanoid, and flavonoid

3 pathways. (A) Pathway diagram. (B) Metabolite abundances and (C) related biosynthetic and regulatory gene expression relative

4 to GLRaV (-) in identical rootstock and at same developmental stage. Notation requires the direction (up/down-regulation) of the

5 effect to be consistent in both years, even if a significant change occurred in only a single year. Glycosides are abbreviated: glu,

6 3-O-glucoside; glucur, 3-O-glucuronide; rut, 3-O-rutinoside. One asterisk, differentially expressed/abundant in one year; Two

7 asterisks, differentially expressed/abundant in both years. One or two " $r$ ", the effects of a particular GLRaV infection differs 
1 between rootstocks at the same developmental stage. PAL, phenylalanine ammonia-lyase; $\mathrm{C} 4 \mathrm{H}$, trans-cinnamate 4-

2 monooxygenase; C3H, p-coumarate 3-hydroxylase; F5H, ferulate-5-hydroxylase; 4CL, 4-coumaroyl-CoA ligase; CCR,

3 cinnamoyl-CoA reductase; CAD, Cinnamyl alcohol dehydrogenase; STS, stilbene synthase; CHS, chalcone synthase; CHI,

4 chalcone isomerase; I2'H, Isoflavone 2'-hydroxylase; IR, Isoflavone reductase; F3H, flavonone 3-hydroxylase; FLS, flavonol

5 synthase; F3'H, flavonoid 3'-monooxygenase; F3'5'H, flavonoid 3',5'-hydroxylase; OMT, O-methyltransferase; DFR,

6 dihydroflavanol 4-reductase; LAR, leucoanthocyanidin reductase; LDOX, Leucoanthocyanidin dioxgenase; UFGT, UDP-

7 glucose:anthocyanidin/flavonoid 3-O-glucosyltransferase; ANR, anthocyanidin reductase; GST4, Glutathione S-transferase 4;

8 AOMT, Anthocyanin O-methyltransferase; AAT, Anthocyanin acyl-transferase; RT, UDP-rhamnose : rhamnosyltransferase. The

9 pathway annotation is based on KEGG pathways (www.genome.jp/kegg/pathway.html, accessed February 13, 2021) and Blanco-

10 Ulate et al., 2017. 


\section{Discussion}

Grapevine leafroll-associated viruses affect viticulture on nearly every continent (Habili

\& Nutter, 1997; Akbaş et al., 2007; Fiore et al., 2008; Mahfoudhi et al., 2008; Golino et al.,

4 2008a; Charles et al., 2009; Jooste et al., 2015) and can cause considerable economic impact on

5 a major crop.

6 The presence and severity of symptoms in GLRaV-infected grapevines is influenced by host

7 genotype, rootstock, which GLRaV is present, and environmental conditions. In addition to the

8 assembly and annotation of the Cabernet franc genome, a valuable resource that might be applied

9 for the larger purpose of understanding grapevine genomic diversity and evolution, the dedicated

10 experimental vineyard used in this study is a tremendous asset for the study of GLRaV infections

11 over time in a common environment. This work identified responses to GLRaVs in grape berries

12 during ripening, including those that are conserved given different GLRaVs and rootstocks and

13 responses that differ based on the rootstock present. We propose which hormones and signaling

14 pathways at least partially govern the responses observed and likely influence leafroll disease

15 symptoms.

16 The effects of dual infections, particularly GLRaV-1,2 (+), were most distinctive. All of

17 the leafroll viruses selected for this study belong to the Closteroviridae family and all but one

18 belongs to the Ampelovirus genus; GLRaV-2 belongs to Closterovirus. All of the GLRaVs used

19 in this study contain a relatively consistent replication gene block (RGB) but are markedly

20 diverse outside of the RGB (Naidu et al., 2015). In addition to host genotype and environment,

21 the sequences downstream of the RGB may account for the disparities in responses observed

22 between infection types. These sequences encode a quintuple gene block and/or viral suppressors

23 of host RNA silencing (VSRs; Naidu et al., 2015). Some of are characterized (Gouveia et al.),

24 but most are not. Further research might determine their specific effects and relationship to host

25 cellular machinery (Chapman, 2004; Wu et al., 2010).

Changes in the expression of NBS-LRR genes were among the conserved responses to

27 GLRaVs and were the single largest category of genes among them. NBS-LRR genes confer

28 resistance to powdery and downy mildew in grapevine (Riaz et al., 2011; Zini et al., 2019). The

29 abundance of these genes varies among Vitis species and are particularly dense at resistance loci

30 (Cochetel et al., 2021). Hypersensitive response (HR) to viruses is mediated by R genes. SA

31 subsequently accumulates and pathogenesis-related gene expression increases for systemic 
1 acquired resistance. HR is a means of prohibiting pathogen spread and can confer resistance

2 when a corresponding dominant avirulence protein is produced by the pathogen (Moffett et al.,

3 2002; Balint Kurti, 2019). However, GLRaV infections are systemic, persist over time, and SA

4 does not seem to play a preeminent role in the response to GLRaV infections. In a previous study

5 of GLRaV-3 infections in Cabernet Sauvignon and Carmenère, the authors also remarked on the

6 induction of defense genes but their inability to impede systemic infection (Espinoza et al.,

7 2007b). Both SA and ABA can participate in virus response, though considerably less is

8 understood about the role of ABA (Kunkel \& Brooks, 2002; Koornneef \& Pieterse, 2008;

9 Alazem \& Lin, 2015) and its relationship to NBS-LRRs, specifically. Notably, however, ABA

10 deficiency is associated with an increase in R-gene efficacy in incompatible interactions with

11 Pseudomonas syringae and in a manner independent of SA (Mang et al., 2012).

12 Hormones have been implicated in mediating defense and development-related networks

13 and are overrepresented at network hubs (Amrine et al., 2015; Müller \& Munné-Bosch, 2015;

14 Jiang et al., 2015; Vandereyken et al., 2018). Hormones like ABA, SA, JA, and others act as

15 important signaling molecules during ripening and defense. The pathways engaged under stress

16 are often tailored to particular pathogens and this entails coordination between hormone

17 pathways (Gao et al., 2011; Vos et al., 2015). Interestingly, the effects of GLRaVs on gene

18 expression in several hormone signaling pathways differed between rootstocks. A subsequent

19 effort could be made to measure the abundances of hormones not quantified here, like cytokinin,

20 gibberellin, and ethylene. Of the hormones considered in this study, however, ABA and ABA-

21 GE abundance tended to increase in GLRaV $(+)$ and was influenced by rootstock. ABA can

22 antagonize SA and JA signaling pathways and suppress ROS signaling (Alazem \& Lin, 2015).

23 WRKY transcription factors both regulate and/or are regulated by ABA, SA, and JA (Li, 2004;

24 Jiang \& Deyholos, 2008; Gao et al., 2011; Liu et al., 2015; Xin et al., 2016). SA and ABA both

25 can interact with RNAi, which is a fundamental component of anti-viral defense. $A G O 1$

26 expression is positively correlated with ABA and $m i R 168 a$, which regulates AGO1, contains

27 ABA-responsive regulatory elements in its promoter (Alazem \& Lin, 2015). Levels of ABA and

28 ABA-GE increase in tobacco mosaic virus-infected leaves. One way in which ABA might aid

29 plant defense is by increasing callose deposition to impair virus movement (Alazem \& Lin,

30 2015); a gene encoding callose synthase is upregulated in the leaves of grapevine virus B-

31 infected plants (Chitarra et al., 2018). 
Relatively more is known about ABA's function as a ripening promoter (Wheeler et al.,

2 2009; Koyama et al., 2010), in response to drought stress (Deluc et al., 2009a; Cochetel et al.,

3 2020), and in transmitting long-distance signals from roots to aerial organs and vice versa

4 (Manzi et al., 2015; Ferrandino et al.). In a study of the impact of GLRaV-3 infection, drought

5 stress, and a combination of both on in-vitro grapevine plantlets, individual stresses both induced

6 ABA (Cui et al., 2016). Drought stress increases ABA and induces the flavonoid pathway in

7 both tea plants (Gai et al., 2020) and in grapes (Deluc et al., 2009b). Our findings, in which ABA

8 abundance tends to increase in $\operatorname{GLRaV}(+)$, are different than that observed for Red Blotch virus-

9 infected berries, in which ABA abundance and NCED expression decrease in infected fruits

10 (Blanco-Ulate et al., 2017).

11 The results of our analysis of metabolites associated with the phenylpropanoid and

12 flavonoid pathways are mixed in their consistency with previous work. Though nonsignificant

13 decreases in anthocyanins were observed, anthocyanins significantly increased in several

14 GLRaV $(+)$ conditions, albeit usually in individual years. These findings differed from others;

15 some observed significant decreases in anthocyanins in fruits from GLRaV-infected plants (Lee

16 \& Martin, 2009; Vega et al., 2011) and others observed no significant changes in anthocyanin at

17 harvest (Endeshaw et al., 2014; Alabi et al., 2016). Like Vega et al., (2011), flavonols were

18 elevated in GLRaV (+) and the largest differences versus GLRaV (-) occurred at the first two stages, FLS expression was down-regulated in GLRaV (+) at harvest, and CHS and MYBPA1 expression were up-regulated at véraison and generally down-regulated at harvest.

In this study, changes in the abundance of ABA and related metabolites distinguished the

22 effects of GLRaVs between rootstocks. The parentage of the two rootstocks used in this study,

23 Kober 5BB and MGT 101-14, includes $V$. riparia. The other parents of Kober 5BB and MGT

24 101-14 are $V$. berlandieri and $V$. rupestris, respectively. These rootstocks were developed at different times. MGT 101-14 originated in France in 1882 and Kober 5BB originated in Austria in 1930 (https://fps.ucdavis.edu/). Rootstocks are chosen for the advantages they confer to the

27 scion given a particular set of circumstances, often having to do with resistance to Phylloxera, nematodes, scion vigor, soil type, and abiotic stress tolerance (Tramontini et al., 2013; Corso \& Bonghi, 2014; Warschefsky et al., 2016). Unlike $V$. vinifera, $V$. riparia, $V$. rupestris, and $V$.

30 berlandieri are asymptomatic hosts of GLRaVs (Naidu et al., 2014). Yet, the particularly severe 31 response to GLRaV-1,2 (+) was not entirely unexpected in Kober 5BB-grafted vines (Uyemoto 
1 et al., 2001; Golino et al., 2008b; Alkowni et al., 2011). Differences in wood abnormalities given

2 different rootstocks (including Kober 5BB) have been observed for particular isolates causing

3 grapevine rugose wood disease (Credi, 1997). Notably, nutritional deficiencies in phosphorus,

4 magnesium, and potassium produce symptoms that resemble those typically observed in

5 GLRaV-infected plants (Gohil et al., 2016). Magnesium deficiency tolerance (Livigni et al.,

6 2019), the impact of phosphorus deficiency on canopy growth (Grant \& Matthews, 1996), and

7 potassium uptake and channels are all influenced by rootstock (Wolpert et al., 2005). Potassium

8 uptake, channel activity, and related gene expression are also regulated by ABA (Blatt, 2000;

9 Köhler et al., 2003; Song et al., 2016; Rogiers et al., 2017), and the application of ABA to

10 tomato roots by drip irrigation affects fruit mineral composition (Barickman et al., 2019).

11 Furthermore, elevated levels of potassium are observed in leafroll virus-infected Burger and

12 Sultana and Burger fruits (Kliewer \& Lider, 1976b; Hale \& Woodham, 1979) and in leaf petioles

13 but lower in leaf blades (Cook and Goheen, 1961). Perhaps potassium-deficient and GLRaV (+)

14 phenotypes are similar because they both induce a response governed by ABA that can be fine-

15 tuned by rootstocks. If some portion of scion ABA originates in roots and/or if rootstock can

16 influence scion ABA levels and signaling genes, as observed here and by others (Chitarra et al.,

17 2017). then perhaps this partially accounts for the variation in response observed between

18 rootstocks. This experiment did not include a comprehensive survey of phytohormones, which

19 would be beneficial, but ABA's function in "root-shoot" communication, its role in ripening, and

20 the results here make it a good candidate around which to study the basis of leafroll disease

21 symptom variability going forward. In addition, the transport of RNAs across the graft junction

22 may perform some function that affects scion disease severity, but this remains to be seen in the

23 particular case of GLRaV (Chitarra et al., 2017).

Together, these data support several conclusions. (1) The majority of genes differentially expressed as a consequence of infection or between GLRaV $(+)$ plants with different rootstocks were year-specific. A small subset of effects was consistently observed across experimental

27 conditions and in both years. These shared changes in expression involved genes associated with pathogen detection, ABA signaling and transport, ROS-related signaling, cytoskeleton remodeling, vesicle trafficking, phenylpropanoid metabolism, sugar transport and conjugation,

30 and leucine biosynthetic genes. (2) The impacts of GLRaV-1,2 dual infection on Kober 5BB-

31 grafted vines were the most distinctive and severe. Though there was variation between GLRaV 
1 infections observed, only the effects of GLRaV-1,2 were distinguishable overall from other

2 infections (GLRaV-1 and/or GLRaV-1,3) pre-véraison and at harvest. (3) The particular effects

3 of GLRaVs in plants grafted to different rootstocks were distinguishable overall at every

4 developmental stage. ABA-related variables were among those that best distinguished the

5 responses to GLRaVs in different rootstock conditions. This included the abundance of ABA, the

6 abundance of ABA-GE, and the expression of genes associated with ABA and other hormone

7 signaling pathways. Finally, this work alone is insufficient to recommend the use of one

8 rootstock or another, but the disparity in sensitivity and symptom severity observed in berries

9 from Cabernet franc vines grafted to different rootstocks suggests that rootstock selection

10 generally should be further explored as a strategy to mitigate some of the negative consequences

11 of leafroll virus infections, should vectors of the virus encroach upon a vineyard.

\section{Supplementary Data}

14 Supplementary File S1. Curated list of ABA-related genes. Pilati et al., 2017

Supplementary File S2. Hormone and metabolite retention time and mass information.

Supplementary Fig. S3. Malic acid, moisture content, $\mathrm{pH}$, titratable acidity, weight per berry, yeast assimilable nitrogen (YAN), and total anthocyanins in 2015 and 2016. For most measures in both years, $3<=\mathrm{n}<=9$. Total anthocyanin and moisture content in $2015,2<=\mathrm{n}<=9$. Total

21 soluble solids before harvest in 2017 and 2018, n=6. Groups differences are indicated with non-

22 overlapping letters (Tukey HSD, $\mathrm{P}<0.05$ ).

24 Supplementary Table S4. Cabernet franc assembly and annotation statistics. up and down-regulated in MGT 101-14 grafted plants versus Kober 5BB grafted plants for each GLRaV condition in each year and in both years. 
1 Supplementary File S7. Conserved responses to GLRaVs depicted in Fig. 3B.

3 Supplementary File S8. Abundance of ABA, ABA-GE, and xanthoxin in 2017 and 2018 at

4 véraison, mid-ripening, and at harvest. Abundance of ABA, ABA-GE, and xanthoxin in 2017

5 and 2018 at all four developmental stages. ANOVA tables for all 5 hormones and hormone-

6 related metabolites. Groups with non-overlapping letters are significantly differet (Tukey HSD, P

$7<0.05)$.

8

$9 \quad$ Supplementary Fig. S9. Rootstock-differentiating genes

11 Supplementary Fig. S10. Percent of variation explained by each of the first five MFA

12 components at each developmental stage.

14 Supplementary Table S11. Number of MFA variables positively and negatively correlated with 15 each rootstock-differentiating MFA dimension.

17 Supplementary Fig. S12. Distribution of centered expression for genes, per functional category, 18 correlated to the same rootstock-differentiating MFA dimensions as hormones and hormone19 related metabolites. Results of Kolmogorov-Smirnov test are shown.

21 Supplementary Text S13. Additional description of hormone signaling genes in Figure 8.

23 Supplementary Fig. S14. Centered expression of

24 VITVvi_vCabFran04_v1_P478.ver1.0.g430590, Histone H1, in berries from GLRaV (+) plants 25 grafted to two different rootstocks.

27 Supplementary Fig. S15. All metabolite products measured that are associated with the

28 shikimate, phenylpropanoid, and flavonoid pathways. One asterisk, differentially

29 expressed/abundant in one year; Two asterisks, differentially expressed/abundant in both years.

30 One or two " $r$ ", the effects of a particular GLRaV infection differs between rootstocks at the 31 same developmental stage. 
2 Acknowledgements

This work was funded by the Pierce's Disease and Glassy-winged Sharpshooter Research

4 Board of the California Department of Food and Agriculture (project 17-0417-000-SA). DC was

5 partially supported by the Louis P. Martini Endowment in Viticulture. The authors would like to

6 thank all past and present Cantu lab members who assisted with the laborious process of

7 sampling, deseeding, crushing, and weighing the tissue used in this study, including Abraham

8 Morales-Cruz, Eric Tran, Jerry Lin, Barbara Blanco-Ulate, and Lucero K. Espinoza.

\section{Author contributions}

11 AR, DAG, SEE, MAR, and DC designed the experiments. MAR monitored virus infections. MM

12 designed the sampling procedure and photographed experimental vines. JG and DQ crushed

13 tissue and prepared RNA extracts. RFB prepared the Cabernet franc genomic and RNA

14 sequencing libraries. AM assembled and annotated the Cabernet franc genome. LL created the

15 metabolite acquisition method. AMV and LL generated the metabolite data. AMV analyzed the

16 RNA sequencing data and prepared all the figures. AMV, LL, and DL analyzed the metabolite

17 data. AMV and DC wrote the manuscript. All authors contributed to, read, and approved the

18 final manuscript.

\section{Data availability}

21 The DNA (BioProject PRJNA701939) and RNA (BioProject PRJNA701940) sequencing data

22 that support these findings are available at the National Center for Biotechnology Information

23 (NCBI). A Cabernet franc genome browser and on-line BLAST tool are currently available at

24 http://www.grapegenomics.com. While under review, access to the Cabernet franc genome

25 assembly and feature sequences, primary scaffolds, haplotigs, feature annotations are available at 26 http://169.237.73.197/for_reviewers/Vondras_leafroll. The assembly, annotations, and raw RNA

27 sequencing counts per library and per gene are available at Zenodo

28 (http://doi.org/10.5281/zenodo.4555977). 


\section{References}

2

Akbaş B, Kunter B, Ilhan D. 2007. Occurrence and Distribution of Grapevine Leafrollassociated Viruses 1, 2, 3 and 7 in Turkey. Journal of Phytopathology 155: 122-124.

Alabi OJ, Casassa LF, Gutha LR, Larsen RC, Henick-Kling T, Harbertson JF, Naidu RA. 2016. Impacts of Grapevine Leafroll Disease on Fruit Yield and Grape and Wine Chemistry in a Wine Grape (Vitis vinifera L.) Cultivar (H Gerós, Ed.). Journal of Plant Pathology 11: e0149666.

Alazem M, Lin N-S. 2015. Roles of plant hormones in the regulation of host-virus interactions. Molecular Plant Pathology 16: 529-540.

Alkowni R, Zhang Y-P, Rowhani A, Uyemoto JK, Minafra A. 2011. Biological, molecular, and serological studies of a novel strain of grapevine leafroll-associated virus 2. Virus genes 43: $102-110$.

Altschul SF, Gish W, Miller W, Myers EW, Lipman DJ. 1990. Basic local alignment search tool. Journal of molecular biology 215: 403-410.

Amrine KCH, Blanco-Ulate B, Cantu D. 2015. Discovery of Core Biotic Stress Responsive Genes in Arabidopsis by Weighted Gene Co-Expression Network Analysis. Journal of Plant Pathology 10: e0118731

Anders S, Pyl PT, Huber W. 2015. HTSeq-A Python framework to work with high-throughput sequencing data. Bioinformatics 31: 166-169.

Atallah SS, Gomez MI, Fuchs MF, Martinson TE. 2012. Economic Impact of Grapevine Leafroll Disease on Vitis vinifera cv. Cabernet franc in Finger Lakes Vineyards of New York. American Journal of Enology and Viticulture 63: 73-79.

Balint-Kurti P. 2019. The plant hypersensitive response: concepts, control and consequences. Molecular Plant Pathology 20(8): 1163-1178.

Barickman, Kopsell, Sams. 2019. Applications of Abscisic Acid and Increasing Concentrations of Calcium Affect the Partitioning of Mineral Nutrients between Tomato Leaf and Fruit Tissue. Horticulturae 5(49).

Bertamini M, Muthuchelian K, Nedunchezhian N. 2004. Effect of Grapevine Leafroll on the Photosynthesis of Field Grown Grapevine Plants (Vitis vinifera L. cv. Lagrein). Journal of Phytopathology 152: 145-152.

Bester R, Burger JT, Maree HJ. 2017. Differential expression of miRNAs and associated gene targets in grapevine leafroll-associated virus 3-infected plants. Archives of virology 162: 987996.

Blanco-Ulate B, Hopfer H, Figueroa-Balderas R, Ye Z, Rivero RM, Albacete A, PérezAlfocea F, Koyama R, Anderson MM, Smith RJ, et al. 2017. Red blotch disease alters grape 
berry development and metabolism by interfering with the transcriptional and hormonal regulation of ripening. Journal of Experimental Botany 68: 1225-1238.

Blanco-Ulate B, Vincenti E, Powell ALT, Cantu D. 2013. Tomato transcriptome and mutant analyses suggest a role for plant stress hormones in the interaction between fruit and Botrytis cinerea. Frontiers in plant science 4: 142.

Blatt MR. 2000. $\mathrm{Ca}(2+)$ signalling and control of guard-cell volume in stomatal movements. Current Opinion in Plant Biology 3: 196-204.

Boetzer M, Pirovano W. 2014. SSPACE-LongRead: scaffolding bacterial draft genomes using long read sequence information. BMC Bioinformatics 15: 211.

Bolger AM, Lohse M, Usadel B. 2014. Trimmomatic: a flexible trimmer for Illumina sequence data. Bioinformatics 30: 2114-2120.

Cabaleiro C, Segura A, García-Berrios JJ. 1999. Effects of Grapevine Leafroll-Associated Virus 3 on the Physiology and Must of Vitis vinifera L. cv. Albariño Following Contamination in the Field. American Journal of Enology and Viticulture 50: 40-44.

Chapman EJ. 2004. Viral RNA silencing suppressors inhibit the microRNA pathway at an intermediate step. Genes \& Development 18: 1179-1186.

Charles JG, Froud KJ, van den Brink R, Allan DJ. 2009. Mealybugs and the spread of grapevine leafroll-associated virus $3(\mathrm{GLRaV}-3)$ in a New Zealand vineyard. Australasian Plant Pathology 38: 576-583.

Chin C-S, Peluso P, Sedlazeck FJ, Nattestad M, Concepcion GT, Clum A, Dunn C, O'Malley R, Figueroa-Balderas R, Morales-Cruz A, et al. 2016. Phased diploid genome assembly with single-molecule real-time sequencing. Nature Methods 13: 1050-1054.

Chitarra W, Cuozzo D, Ferrandino A, Secchi F, Palmano S, Perrone I, Boccacci P, Pagliarani C, Gribaudo I, Mannini F, et al. 2018. Dissecting interplays between Vitis vinifera L. and grapevine virus B (GVB) under field conditions. Molecular Plant Pathology 19: 2651-

262666.

27 Chitarra W, Perrone I, Avanzato CG, Minio A, Boccacci P, Santini D, Gilardi G, Siciliano I, Gullino ML, Delledonne M, et al. 2017. Grapevine Grafting: Scion Transcript Profiling and Defense-Related Metabolites Induced by Rootstocks. Frontiers in plant science 8: 654.

30 Cochetel N, Ghan R, Toups HS, Degu A, Tillett RL, Schlauch KA, Cramer GR. 2020. Drought tolerance of the grapevine, Vitis champinii cv. Ramsey, is associated with higher photosynthesis and greater transcriptomic responsiveness of abscisic acid biosynthesis and signaling. BMC Plant Biology https://doi.org/10.1186/s12870-019-2012-7 
chromosome fusion and disease resistance gene expansion during Vitis and Muscadinia divergence. G3 Genes $\mid$ Genomes $\mid$ Genetics: 1-22.

Cook, JA, Goheen AC. 1961. The effect of a virus disease, leafroll, on the mineral composition

Coombe BG. 1995. Growth Stages of the Grapevine: Adoption of a system for identifying grapevine growth stages. Australian Journal of Grape and Wine Research 1: 100-110.

Corso M, Bonghi C. 2014. Grapevine rootstock effects on abiotic stress tolerance. Plant Science

9 Today 1(3): 108-113.

Credi R. 1997. Characterization of Grapevine Rugose Wood Disease Sources from Italy. Plant Disease 81(11): 1288-1292.

Cui Z-H, Bi W-L, Hao X-Y, Xu Y, Li P-M, Walker MA, Wang Q-C. 2016. Responses of In vitro-Grown Plantlets (Vitis vinifera) to Grapevine leafroll-Associated Virus-3 and PEG-Induced Drought Stress. Frontiers in Physiology 7: 203.

Da Silva C, Zamperin G, Ferrarini A, Minio A, Dal Molin A, Venturini L, Buson G, Tononi P, Avanzato C, Zago E, et al. 2013. The high polyphenol content of grapevine cultivar tannat berries is conferred primarily by genes that are not shared with the reference genome. The Plant 18 Cell 25: 4777-4788.

Deluc LG, Quilici DR, Decendit A, Grimplet J, Wheatley MD, Schlauch KA, Mérillon J-M, Cushman JC, Cramer GR. 2009. Water deficit alters differentially metabolic pathways affecting important flavor and quality traits in grape berries of Cabernet Sauvignon and Chardonnay. BMC genomics 10: 212.

DeYoung BJ, Innes RW. 2006. Plant NBS-LRR proteins in pathogen sensing and host defense. Nature Immunology 7: 1243-1249.

Endeshaw ST, Sabbatini P, Romanazzi G, Schilder AC, Neri D. 2014. Effects of grapevine leafroll associated virus 3 infection on growth, leaf gas exchange, yield and basic fruit chemistry of Vitis vinifera L. cv. Cabernet Franc. Scientia Horticulturae 170: 228-236. induced during compatible viral interactions with grapevine and Arabidopsis. Journal of Experimental Botany 58: 3197-3212. expression associated with compatible viral diseases in grapevine cultivars. Functional \& Integrative Genomics 7: 95-110. 
Fiore N, Prodan S, Montealegre J, Aballay E, Pino AM, Zamorano A. 2008. Survey of grapevine viruses in Chile. Journal of Plant Pathology 90: 125-130.

Fuchs M, Almeyda CV, Rwahnih Al M, Atallah SS, Cieniewicz EJ, Farrar K, Foote WR, Safeguard Specialty Crops in the United States. Plant Disease. 105: 14-26 Exogenous abscisic acid induces the lipid and flavonoid metabolism of tea plants under drought stress. Scientific Reports 10:12275.

Gaiteri C, Ding Y, French B, Tseng GC, Sibille E. 2014. Beyond modules and hubs: the potential of gene coexpression networks for investigating molecular mechanisms of complex brain disorders. Genes, Brain and Behavior 13: 13-24.

Gao QM, Venugopal S, Navarre D, Kachroo A. 2011. Low Oleic Acid-Derived Repression of Jasmonic Acid-Inducible Defense Responses Requires the WRKY50 and WRKY51 Proteins.

14 Plant Physiology 155: 464-476.

Gehlenborg N. 2019. UpSetR: A More Scalable Alternative to Venn and Euler Diagrams for Visualizing Intersecting Sets. R package version 1.4.0. https://CRAN.R-

17 project.org/package $=$ UpSetR

Goff KE, Ramonell KM. 2007. The role and regulation of receptor-like kinases in plant defense. Gene regulation and systems biology 1: 167-175.

20 Golino D, Weber E, Sim S, Rowhani A. 2008a. Leafroll disease is spreading rapidly in a Napa Valley vineyard. California Agriculture 62(4): 156-160.

22 Golino DA. 1993. Potential Interactions Between Rootstocks and Grapevine Latent Viruses. American Journal of Enology and Viticulture 44(2): 148-152.

24 Golino DA, Wolpert J, Sim ST, Benz J, Anderson M, Rowhani A. 2008b. Virus effects on 25 vine growth and fruit components of Cabernet Sauvignon on six rootstocks. Proceedings of the 26 2nd Annual National Viticulture Research Conference. University of California, Davis 28-29.

27 Gouveia P, Nolasco G, 2012. The p19.7 RNA silencing suppressor from Grapevine leafroll-

28 associated virus 3 shows different levels of activity across phylogenetic groups. Virus Genes $\mathbf{4 5}$ :

$29 \quad 333-339$

30 Grant RS, Matthews MA. 1996. The Influence of Phosphorus Availability and Rootstock on 31 Root System Characteristics, Phosphorus Uptake, Phosphorus Partitioning, and Growth

32 Efficiency. American Journal of Enology and Viticulture 47: 403-409.

33 Grimplet J, Cramer GR, Dickerson JA, Mathiason K, Van Hemert J, Fennell AY. 2009.

34 VitisNet: 'Omics' integration through grapevine molecular networks. PLoS ONE 4(12): e8365. 
Gu Y, Innes RW. 2011. The KEEP ON GOING Protein of Arabidopsis Recruits the ENHANCED DISEASE RESISTANCE1 Protein to Trans-Golgi Network/Early Endosome Vesicles. Plant Physiology 155: 1827-1838.

Guidoni S, Mannini F, Ferrandino A, Argamante N, Di Stefano R. 1997. The Effect of Grapevine Leafroll and Rugose Wood Sanitation on Agronomic Performance and Berry and Leaf Phenolic Content of a Nebbiolo Clone (Vitis vinifera L.). American Journal of Enology and

7 Viticulture 48: 438-442.

Guidoni S, Mannini F, Ferrandino A, Argamante N, Di Stefano R. 2000. Effect of virus status on leaf and berry phenolic compounds in two wine grapevine vitis vinifera cultivars. $V$ ISHS Acta Horticulturae. International Symposium on Grapevine Physiology. Jerusalem, Israel. 526: 445-452.

Gutha LR, Casassa LF, Harbertson JF, Naidu RA. 2010. Modulation of flavonoid biosynthetic pathway genes and anthocyanins due to virus infection in grapevine ( Vitis vinifera L.) leaves. BMC Plant Biology 10: 187.

Haas BJ, Delcher AL, Mount SM, Wortman JR, Smith RK Jr, Hannick LI, Maiti R, Ronning CM, Rusch DB, Town CD, et al. 2003. Improving the Arabidopsis genome annotation using maximal transcript alignment assemblies. Nucleic Acids Research 31: 5654-5666.

Haas BJ, Salzberg SL, Zhu W, Pertea M, Allen JE, Orvis J, White O, Buell CR, Wortman JR. 2008. Automated eukaryotic gene structure annotation using EVidenceModeler and the Program to Assemble Spliced Alignments. Genome biology 9: R7

Habili N, Nutter FW Jr. 1997. Temporal and Spatial Analysis of Grapevine LeafrollAssociated Virus 3 in Pinot Noir Grapevines in Australia. Plant Disease 81(6): 625-628

Hale CR, Woodham RC. 1979. Effect of Grapevine Leafroll Disease on the Acid and Potassium Composition of Sultana Grapes. American Journal of Enology and Viticulture 30: 9192.

Haxim Y, Ismayil A, Jia Q, Wang Y, Zheng X, Elife TC, 2017. Autophagy functions as an antiviral mechanism against geminiviruses in plants. elifesciences doi: 10.7554/eLife.23897

Hill DA. 2001. Influence of linker histone $\mathrm{H} 1$ on chromatin remodeling. Biochemistry and cell biology 79: 317-324.

Hirayama T, Shinozaki K. 2010. Research on plant abiotic stress responses in the post-genome era: past, present and future. Plant Journal 61: 1041-1052.

Huang J, Zhu C, Li X. 2018. SCFSNIPER4 controls the turnover of two redundant TRAF proteins in plant immunity. Plant Journal 95: 504-515. 
Jaillon O, Aury J-M, Noel B, Policriti A, Clepet C, Casagrande A, Choisne N, Aubourg S, Vitulo N, Jubin C, et al. 2007. The grapevine genome sequence suggests ancestral hexaploidization in major angiosperm phyla. Nature 449: 463-467. Sensitive (SOS) Pathway: Established and Emerging Roles. Molecular Plant 6: 275-286.

Jiang F, Hartung W. 2008. Long-distance signalling of abscisic acid (ABA): the factors regulating the intensity of the ABA signal. Journal of Experimental Botany 59: 37-43.

Jiang Y, Deyholos MK. 2009. Functional characterization of Arabidopsis NaCl-inducible WRKY25 and WRKY33 transcription factors in abiotic stresses. Plant Molecular Biology 69:

13 91-105.

Jiang Z, Dong X, Zhang Z. 2015. Network-Based Comparative Analysis of Arabidopsis Immune Responses to Golovinomyces orontii and Botrytis cinerea Infections. Scientific Reports: 6(19149): $1-11$ Mitchell A, Nuka G, et al. 2014. InterProScan 5: genome-scale protein function classification. Bioinformatics 30: 1236-1240.

Jooste AEC, Molenaar N, Maree HJ, Bester R, Morey L, de Koker WC, Burger JT. 2015. Identification and distribution of multiple virus infections in Grapevine leafroll diseased vineyards. European Journal of Plant Pathology 142: 363-375.

Kim D, Langmead B, Salzberg SL. 2015. HISAT: a fast spliced aligner with low memory requirements. Nature Methods 12: 357-360.

Klaassen VA, Sim ST, Dangl GS, Osman F, Rwahnih Al M, Rowhani A, Golino DA. 2011. Vitis californica and Vitis californica $\times$ Vitis vinifera Hybrids are Hosts for Grapevine leafrollassociated virus-2 and -3 and Grapevine virus A and B. Plant Disease 657-665

Kliewer WM, Lider LA. 1976. Influence of Leafroll Virus on Composition of Burger Fruits. American Journal of Enology and Viticulture 27: 118-124.

Kolde R. 2019. pheatmap: Pretty Heatmaps. R package version 1.0.12. https://CRAN.Rproject.org/package= pheatmap 
Koornneef A, Pieterse CMJ. 2008. Cross Talk in Defense Signaling. Plant Physiology 146: 839-844.

Korf I. 2004. Gene finding in novel genomes. BMC Bioinformatics 5: 59

Kovacs LG, Hanami H, Fortenberry M, Kaps ML. 2001. Latent Infection by Leafroll Agent GLRaV-3 Is Linked to Lower Fruit Quality in French-American Hybrid Grapevines Vidal blanc and St. Vincent. American Journal of Enology and Viticulture 52(3): 254-259.

Koyama K, Sadamatsu K, Goto-Yamamoto N. 2010. Abscisic acid stimulated ripening and gene expression in berry skins of the Cabernet Sauvignon grape. Functional \& Integrative

9 Genomics 10: 367-381.

Köhler B, Hills A, Blatt MR. 2003. Control of guard cell ion channels by hydrogen peroxide and abscisic acid indicates their action through alternate signaling pathways. Plant Physiology 131: $385-388$.

Kunkel BN, Brooks DM. 2002. Cross talk between signaling pathways in pathogen defense. Current Opinion in Plant Biology 5: 325-331.

Le S, Josse J, Husson F. 2008. FactoMineR: An R Package for Multivariate Analysis. Journal of Statistical Software 25(1), 1-18. 10.18637/jss.v025.i01

Lee J, Martin RR. 2009. Influence of grapevine leafroll associated viruses (GLRaV-2 and -3) on the fruit composition of Oregon Vitis vinifera L. cv. Pinot noir: Phenolics. Food Chemistry 112: 889-896.

Lee J, Keller KE, Rennaker C, Martin RR. 2009. Influence of grapevine leafroll associated viruses (GLRaV-2 and -3) on the fruit composition of Oregon Vitis vinifera L. cv. Pinot noir: Free amino acids, sugars, and organic acids. Food Chemistry 117: 99-105. Mediated and Salicylate-Mediated Signals in Plant Defense. The Plant Cell 16: 319-331.

25 Li Q, Hu A, Qi J, Dou W, Qin X, Zou X, Xu L, Chen S, He Y. 2020. CsWAKL08, a pathogen-induced wall-associated receptor-like kinase in sweet orange, confers resistance to citrus bacterial canker via ROS control and JA signaling. Horticulture Research 7(42): 1-15. interactions reveals folding principles of the human genome. Science 326: 289-293.

31 Liu S, Kracher B, Ziegler J, Birkenbihl RP, Somssich IE. 2015. Negative regulation of ABA 
Livigni S, Lucini L, Sega D, Navacchi O, Pandolfini T, Zamboni A, Varanini Z. 2019. The different tolerance to magnesium deficiency of two grapevine rootstocks relies on the ability to cope with oxidative stress. BMC Plant Biology 19: 148

Lomsadze A, Ter-Hovhannisyan V, Chernoff YO, Borodovsky M. 2005. Gene identification in novel eukaryotic genomes by self-training algorithm. Nucleic Acids Research. 33(20): 64946506.

Love MI, Huber W, Anders S. 2014. Moderated estimation of fold change and dispersion for RNA-seq data with DESeq2. Genome biology 15(550): 1-21

Lyzenga WJ, Liu H, Schofield A, Muise-Hennessey A, Stone SL. 2013. Arabidopsis CIPK26 interacts with KEG, components of the ABA signalling network and is degraded by the ubiquitin-proteasome system. Journal of Experimental Botany 64: 2779-2791.

Mahfoudhi N, Digiaro M, Dhouibi MH. 2008. Incidence and Distribution of Grapevine Leafroll-associated viruses in Tunisian Vineyards. Journal of Phytopathology 156: 556-558.

Mandadi KK, Scholthof K-BG. 2013. Plant Immune Responses Against Viruses: How Does a Virus Cause Disease? The Plant Cell 25: 1489-1505.

Mang H-G, Qian W, Zhu Y, Qian J, Kang H-G, Klessig DF, Hua J. 2012. Abscisic Acid

Nuclear Accumulation of Resistance Proteins SNC1 and RPS4 in Arabidopsis. The Plant Cell 24: $1271-1284$.

Manzi M, Lado J, Rodrigo MJ, Zacarías L, Arbona V, Gómez-Cadenas A. 2015. Root ABA Accumulation in Long-Term Water-Stressed Plants is Sustained by Hormone Transport from Aerial Organs. Plant and Cell Physiology 56(12): 2457-2466.

Massonnet M, Cochetel N, Minio A, Vondras AM, Lin J, Muyle A, Garcia JF, Zhou Y, Delledonne M, Riaz S, et al. 2020. The genetic basis of sex determination in grapes. Nature Communications 11: 2902.

Minio A, Massonnet M, Figueroa-Balderas R, Castro A, Cantu D. 2019a. Diploid Genome Assembly of the Wine Grape Carménère. G3 Genes|Genomes|Genetics 9: 1331-1337. Development. G3 Genes|Genomes|Genetics 9: 755-767.

Moffett P, Farnham G, Peart J, Baulcombe DC. 2002. Interaction between domains of a plant NBS-LRR protein in disease resistance-related cell death. The EMBO Journal 21: 4511-4519. 
Moon JY, Park JM. 2016. Cross-Talk in Viral Defense Signaling in Plants. Frontiers in Microbiology 7: 2068

Morant AV, Jørgensen K, Jørgensen C, Paquette SM, Sánchez-Pérez R, Møller BL, Bak S. 2008. $\beta$-Glucosidases as detonators of plant chemical defense. Phytochemistry 69: 1795-1813.

Moreno-Moyano LT, Bonneau JP, Sánchez-Palacios JT, Tohme J, Johnson AAT. 2016. Association of Increased Grain Iron and Zinc Concentrations with Agro-morphological Traits of Biofortified Rice. Frontiers in plant science 7: 1463.

Morita-Yamamuro C, Tsutsui T, Sato M, Yoshioka H, Tamaoki M, Ogawa D, Matsuura H, Yoshihara T, Ikeda A, Uyeda I, et al. 2005. The Arabidopsis Gene CAD1 Controls Programmed Cell Death in the Plant Immune System and Encodes a Protein Containing a MACPF Domain. Plant and Cell Physiology 46: 902-912.

Müller M, Munné-Bosch S. 2015. Ethylene Response Factors: A Key Regulatory Hub in Hormone and Stress Signaling. Plant Physiology 169: 32-41.

Myers G. 2014. Efficient Local Alignment Discovery amongst Noisy Long Reads.Brown D, Morgenstern B eds. Wroclaw, Poland: Springer, Berlin, Heidelberg, 52-67.

Naidu R, Rowhani A, Fuchs M, Golino D, Martelli GP. 2014. Grapevine Leafroll: A Complex

Naidu RA, Maree HJ, Burger JT. 2015. Grapevine Leafroll Disease and Associated Viruses: A Unique Pathosystem. Annual Review of Phytopathology 53: 613-634.

Nozoye T. 2018. The Nicotianamine Synthase Gene Is a Useful Candidate for Improving the Nutritional Qualities and Fe-Deficiency Tolerance of Various Crops. Frontiers in plant science 9: 340 .

Osman F, Leutenegger C, Golino D, Rowhani A. 2008. Comparison of low-density arrays, RT-PCR and real-time TaqMan RT-PCR in detection of grapevine viruses. Journal of

25 Virological Methods 149: 292-299.

Otulak-Kozieł K, Kozieł E, Valverde RA. 2019. The Respiratory Burst Oxidase Homolog D (RbohD) Cell and Tissue Distribution in Potato-Potato Virus Y (PVYNTN) Hypersensitive and Susceptible Reactions. International Journal of Molecular Sciences 20: 2741.

Pan X, Welti R, Wang X. 2010. Quantitative analysis of major plant hormones in crude plant extracts by high-performance liquid chromatography-mass spectrometry. Nature Protocols 5:

31 986-992. 
Pereira JM, Correia CM, Gonçalves B, Bacelar EA, Coutinho JF, Ferreira HF, Lousada JL, Cortez MI. 2012. Impacts of leafroll-associated viruses (GLRaV-1 and -3) on the physiology of the Portuguese grapevine cultivar 'Touriga Nacional' growing under field conditions. Annals of Applied Biology 160: 237-249.

StringTie enables improved reconstruction of a transcriptome from RNA-seq reads. Nature biotechnology 33: 290-295.

Pilati S, Bagagli G, Sonego P, Moretto M, Brazzale D, Castorina G, Simoni L, Tonelli C, Guella G, Engelen K, et al. 2017. Abscisic Acid Is a Major Regulator of Grape Berry Ripening Onset: New Insights into ABA Signaling Network. Frontiers in plant science 8: 1093.

Poojari S, Alabi OJ, Naidu RA. 2013. Molecular characterization and impacts of a strain of Grapevine leafroll-associated virus 2 causing asymptomatic infection in a wine grape cultivar.

13 Virology Journal 10: 324.

Postnikova OA, Nemchinov LG. 2012. Comparative analysis of microarray data in Arabidopsis transcriptome during compatible interactions with plant viruses. Virology Journal 9: 101.

Prosser SW, Goszczynski DE, Meng B. 2007. Molecular analysis of double-stranded RNAs reveals complex infection of grapevines with multiple viruses. Virus Research 124: 151-159.

R Core Team 2020. R: A language and environment for statistical computing. R Foundation for Statistical Computing, Vienna, Austria. URL https://www.R-project.org/.

RStudio Team 2020. RStudio: Integrated Development for R. RStudio, PBC, Boston, MA URL http://www.rstudio.com/.

Ram K, Wickham H. 2018. wesanderson: A Wes Anderson Palette Generator. R package version 0.3.6. https://CRAN.R-project.org/package=wesanderson

Reddy AS, Day IS. 2001. Kinesins in the Arabidopsis genome: A comparative analysis among eukaryotes. BMC genomics: 2: 1-13.

Riaz S, Tenscher AC, Ramming DW, Walker MA. 2011. Using a limited mapping strategy to identify major QTLs for resistance to grapevine powdery mildew (Erysiphe necator) and their use in marker-assisted breeding. Theoretical and Applied Genetics 122: 1059-1073.

Ricketts KD, Gomez MI, Atallah SS, Fuchs MF, Martinson TE, Battany MC, Bettiga LJ, Cooper ML, Verdegaal PS, Smith RJ. 2015. Reducing the Economic Impact of Grapevine Journal of Enology and Viticulture 66: 138-147. inbreeding in the grapevine cultivar Chardonnay (PM Richardson, Ed.). PLOS Genetics 14(11): e1007807. 
Rodrigo G, Carrera J, Ruiz-Ferrer V, del Toro FJ, Llave C, Voinnet O, Elena SF. 2012. A Meta-Analysis Reveals the Commonalities and Differences in Arabidopsis thaliana Response to Different Viral Pathogens. PLoS ONE 7(7): e40526. doi:10.1371/journal.pone.0040526

Rogiers SY, Coetzee ZA, WALKER RR, Deloire A, Tyerman SD. 2017. Potassium in the Grape (Vitis vinifera L.) Berry: Transport and Function. Frontiers in plant science 8: 1629. Leafroll Associated Virus-3: Effects on Rootstocks, Vine Performance, Yield and Berries. Department of Plant Pathology, University of Californis, Davis, CA 95616, U.S.A

Rudis B. 2020. hrbrthemes: Additional Themes, Theme Components and Utilities for 'ggplot2'. R package version 0.8.0. https://CRAN.R-project.org/package=hrbrthemes

Rwahnih Al M, Alabi OJ, Westrick NM, Golino D, Rowhani A. 2017. Description of a Novel Monopartite Geminivirus and Its Defective Subviral Genome in Grapevine. Phytopathology. 107: $240-251$

Rwahnih Al M, Daubert S, Golino D, Rowhani A. 2009. Deep sequencing analysis of RNAs from a grapevine showing Syrah decline symptoms reveals a multiple virus infection that includes a novel virus. Virology 387: 395-401.

Seo S, Ishizuka K, Ohashi Y. 1995. Induction of salicylic acid $\beta$-glucosidase in tobacco leaves by exogenous salicylic acid. Plant Cell Physiol. 36: 447-453.

Shaik R, Ramakrishna W. 2013. Genes and Co-Expression Modules Common to Drought and Bacterial Stress Responses in Arabidopsis and Rice. PLoS ONE 8(10): e77261. doi:10.1371/journal.pone.0077261 AMP1 mediates abscisic acid and abiotic stress responses in Arabidopsis. New Phytologist 199: $135-150$.

Skubacz A, Daszkowska-Golec A, Szarejko I. 2016. The Role and Regulation of ABI5 (ABAInsensitive 5) in Plant Development, Abiotic Stress Responses and Phytohormone Crosstalk. Frontiers in plant science 7: 1884.

Slater GSC, Birney E. 2005. Automated generation of heuristics for biological sequence comparison. BMC Bioinformatics 6:31.

30 Smit A, Hubley R, Green P. RepeatMasker Open-4.0. 2013-2015

$31<\mathrm{http}: / /$ www.repeatmasker.org $>$.

32 Song M, Wang S, Chai L, Zhang S, Shen Y. 2016. Characterization of an ABA-Induced and $33 \mathrm{~K}+$ Channel Gene FaKAT1 that Regulates Strawberry Fruit Ripening. Journal of Plant Growth 34 Regulation 36: 312-322. 
Stanke M, Keller O, Gunduz I, Hayes A, Waack S, Morgenstern B. 2006. AUGUSTUS: ab initio prediction of alternative transcripts. Nucleic Acids Research 34: W435-W439.

Stone SL, Williams LA, Farmer LM, Vierstra RD, Callis J. 2006. KEEP ON GOING, a RING E3 ligase essential for Arabidopsis growth and development, is involved in abscisic acid signaling. The Plant Cell 18: 3415-3428.

Sun J-H, Dong Y-H, Li C-L, Shen Y-Y. 2015. Transcription and enzymatic analysis of betaglucosidase VvBG1 in grape berry ripening. Plant Growth Regulation 75: 67-73.

8 Tramontini S, Vitali M, Centioni L, Schubert A, Lovisolo C. 2013. Rootstock control of scion 9 response to water stress in grapevine. Environmental and Experimental Botany 93: 20-26.

Trupkin SA, Auge GA, Zhu JK, Sanchez RA, Botto JF. 2017. SALT OVERLY SENSITIVE 2 (SOS2) and interacting partners SOS3 and ABSCISIC ACID-INSENSITIVE 2 (ABI2) promote red-light-dependent germination and seedling deetiolation in Arabidopsis. Int. J. Plant Sci. 178(6):485-493.

Uyemoto J, Rowhani A, Luvisi D, Krag C. 2001. New closterovirus in 'Redglobe' grape causes decline of grafted plants. California Agriculture 55(4): 28-31.

Vandereyken K, Van Leene J, De Coninck B, Cammue BPA. 2018. Hub Protein Controversy:

Vega A, Gutiérrez RA, Peña-Neira A, Cramer GR, Arce-Johnson P. 2011. Compatible GLRaV-3 viral infections affect berry ripening decreasing sugar accumulation and anthocyanin biosynthesis in Vitis vinifera. Plant Molecular Biology 77: 261-274. Corvina unveils varietal diversity. BMC genomics 14: 41.

Vondras AM, Minio A, Blanco-Ulate B, Figueroa-Balderas R, Penn MA, Zhou Y, Seymour D, Ye Z, Liang D, Espinoza LK, et al. 2019. The genomic diversification of grapevine clones. BMC Genomics. 20:972

Vos IA, Moritz L, Pieterse CMJ, Van Wees SCM. 2015. Impact of hormonal crosstalk on plant resistance and fitness under multi-attacker conditions. Frontiers in plant science 6: 639

Wheeler S, Loveys B, Ford C, Davies C. 2009. The relationship between the expression of abscisic acid biosynthesis genes, accumulation of abscisic acid and the promotion of Vitis viniferaL. berry ripening by abscisic acid. Australian Journal of Grape and Wine Research 15: 195-204. 
1 Wickham H. 2016. ggplot2: Elegant Graphics for Data Analysis. Springer-Verlag New York

2 Wolpert JA, Smart DR, Anderson M. 2005. Lower Petiole Potassium Concentration at Bloom 3 in Rootstocks with Vitis berlandieri Genetic Backgrounds. American Journal of Enology and

4 Viticulture 56: 163-169.

5 Wu Q, Wang X, Ding S-W. 2010. Viral suppressors of RNA-based viral immunity: host targets.

6 Cell Host \& Microbe 8: 12-15.

7 Xin PF, Gao CS, Cheng CH, Tang Q, Dong ZX, Zhao LN, Zang GG. 2016. Identification

8 and characterization of hemp WRKY transcription factors in response to abiotic stresses.

9 Biologia Plantarum 60: 489-495.

10 Yoshimoto K, Hanaoka H, Sato S, Kato T, Tabata S, Noda T, Ohsumi Y. 2004. Processing 11 of ATG8s, Ubiquitin-Like Proteins, and Their Deconjugation by ATG4s Are Essential for Plant 12 Autophagy. The Plant Cell 16: 2967-2983.

13 Yu G, Wang L-G, Han Y, He Q-Y. 2012. clusterProfiler: an R package for comparing 14 biological themes among gene clusters. OMICS: A Journal of Integrative Biology 16(5):284-287

15 Zhang G, Duan C, Wang Y, Wang Y, Ji K, Xu H, Dai S, Li Q, Chen P, Sun Y, et al. 2013.

16 The expression pattern of $\beta$-glucosidase genes (VvBGs) during grape berry maturation and

17 dehydration stress. Plant Growth Regulation 70: 105-114.

18 Zhou X, Hao H, Zhang Y, Bai Y, Zhu W, Qin Y, Yuan F, Zhao F, Wang M, Hu J, et al. 19 2015. SOS2-LIKE PROTEIN KINASE5, an SNF1-RELATED PROTEIN KINASE3-Type

20 Protein Kinase, Is Important for Abscisic Acid Responses in Arabidopsis through

21 Phosphorylation of ABSCISIC ACID-INSENSITIVE5. Plant Physiology 168: 659-676.

22 Zini E, Dolzani C, Stefanini M, Gratl V, Bettinelli P, Nicolini D, Betta G, Dorigatti C, 23 Velasco R, Letschka T, et al. 2019. R-Loci Arrangement Versus Downy and Powdery Mildew 24 Resistance Level: A Vitis Hybrid Survey. International Journal of Molecular Sciences 20: 3526. 